\title{
Comparison of the Properties of Natural Sorbents for the Calcium Looping Process
}

\author{
Krzysztof Labus
}

check for

updates

Citation: Labus, K. Comparison of the Properties of Natural Sorbents for the Calcium Looping Process.

Materials 2021, 14, 548. https:// doi.org/10.3390/ma14030548

Academic Editors: Sergey V. Ushakov Received: 1 January 2021

Accepted: 20 January 2021

Published: 24 January 2021

Publisher's Note: MDPI stays neutral with regard to jurisdictional claims in published maps and institutional affiliations.

Copyright: (C) 2021 by the author. Licensee MDPI, Basel, Switzerland. This article is an open access article distributed under the terms and conditions of the Creative Commons Attribution (CC BY) license (https:/ / creativecommons.org/licenses/by/ $4.0 /)$.
Department of Applied Geology, Silesian University of Technology, 2 Akademicka St., 44-100 Gliwice, Poland; krzysztof.labus@polsl.pl

\begin{abstract}
Capturing $\mathrm{CO}_{2}$ from industrial processes may be one of the main ways to control global temperature increases. One of the proposed methods is the calcium looping technology (CaL). The aim of this research was to assess the sequestration capacity of selected carbonate rocks, serpentinite, and basalt using a TGA-DSC analysis, thus simulating the CaL process. The highest degrees of conversion were obtained for limestones, lower degrees were obtained for magnesite and serpentinite, and the lowest were obtained for basalt. The decrease in the conversion rate, along with the subsequent CaL cycles, was most intense for the sorbents with the highest values. Thermally pretreated limestone samples demonstrated different degrees of conversion, which were the highest for the calcium-carbonate-rich limestones. The cumulative carbonation of the pretreated samples was more than twice as low as that of the raw ones. The thermal pretreatment was effective for the examined rocks.
\end{abstract}

Keywords: TGA-DSC; calcium looping; $\mathrm{CO}_{2}$ capture; mineral carbonation; natural sorbents; carbonate rock; serpentine

\section{Introduction}

The prevailing view today is that anthropogenic and geogenic greenhouse gases (GHGs) emitted into the atmosphere are the main cause of global warming. Energy production and use may be responsible for almost two-thirds of global greenhouse gas emissions (e.g., [1]). $\mathrm{CO}_{2}$ is considered to be the greenhouse gas with the greatest contribution to global warming, and global $\mathrm{CO}_{2}$ emissions are used as a clear indicator of global fossil energy consumption (e.g., [2]). Given the above assumptions, it can be concluded that capturing $\mathrm{CO}_{2}$ from industrial processes may be one of the main ways to control global temperature increases.

Mineral carbonation (MC) is considered to be one of the safest technologies for reducing $\mathrm{CO}_{2}$ emissions into the atmosphere and is used to capture and store $\mathrm{CO}_{2}$ in situ-in geological formations-or ex situ-as a potential solution for $\mathrm{CO}_{2}$ sequestration from smaller emitters where geological sequestration is not a viable option [3].

The advantage of mineral carbonation is the permanent storage of $\mathrm{CO}_{2}$ in the form of thermodynamically stable and environmentally friendly carbonates (e.g., [4-6]). This process is exothermic, and the raw materials for its operation are widely available (which is advantageous from an economic point of view) [7]. In the MC process, appropriately selected mineral substrates react with $\mathrm{CO}_{2}$ and form thermodynamically stable carbonates. This prevents emissions and ensures permanent $\mathrm{CO}_{2}$ sequestration [8,9]. One of proposed ex situ methods is the calcium looping technology-CaL [10].

Calcium looping $(\mathrm{CaL})$ systems have been proposed as a less expensive method of $\mathrm{CO}_{2}$ capture for conventional power plants. In this process, a key role is played by calcium sorbent, which is used in alternating calcination and carbonation processes. The efficiency of the process varies depending on the properties of the sorbents used, which are expressed, inter alia, in the effects observed for the decreasing efficiency of gas capture with increasing 
number of CaL cycles. It is believed that this phenomenon is related to the reduction of the active surface of the sorbent due to sintering and, possibly, the decrease in the chemical activity resulting from the reaction with sulfur oxides competing with carbonation. The reaction in which sulfur compounds are involved is largely similar to carbonation; however, it is irreversible under $\mathrm{CaL}$ conditions. It takes place in pores of small dimensions, and its products are deposited on the sorbent surface, which, in turn, makes carbonation difficult. The environments of carbonation are meso- and micropores, and especially in the latter ones, rapid filling with reaction products can take place [11].

The aim of this work was to assess the sequestration capacity of selected rocks using a simultaneous TGA-DSC analysis, thus simulating the calcium looping process. Such a method is suitable for small samples (e.g., drill cuttings, rock fragments), which are easy to obtain even at a very early stage of the raw material deposit recognition. Moreover, such tests do not require extensive reactors, and, in a relatively quick and simple way, they allow for the characterization of the material or screening of samples in terms of their suitability for CaL.

The calcium looping process-shown in Figure 1—uses a reversible chemical reaction,

$$
\mathrm{CaO}+\mathrm{CO}_{2}=\mathrm{CaCO}_{3}
$$

between lime $(\mathrm{CaO})$ and $\mathrm{CO}_{2}$, to capture $\mathrm{CO}_{2}$ from waste gas streams [10]. $\mathrm{CO}_{2}$ in the gas stream reacts with $\mathrm{CaO}$ in an exothermic carbonation reaction, forming calcium carbonate $\left(\mathrm{CaCO}_{3}\right)$ at temperatures in the range of $600-700^{\circ} \mathrm{C}$. The $\mathrm{CaCO}_{3}$ from the carbonizer is then sent to a separate device called a calciner, where the calcination reaction takes place at a high temperature (around $900{ }^{\circ} \mathrm{C}$ ). In these conditions, high-purity $\mathrm{CO}_{2}$ is released, which is suitable for transport to the sequestration site. The $\mathrm{CaO}$ produced is then sent back to the carbonator, closing the loop. Many researchers have proposed the oxy-combustion of coal in a calciner as a heat source for the calcination reaction [10,12]. The heat can be recovered from the exothermic carbonation reaction as well as from high-temperature gas and solid waste streams to generate electricity. As a result, $\mathrm{CaL} \mathrm{CO}$ capture technology can be less energy intensive and more economical than the amine-based chemical absorption process.

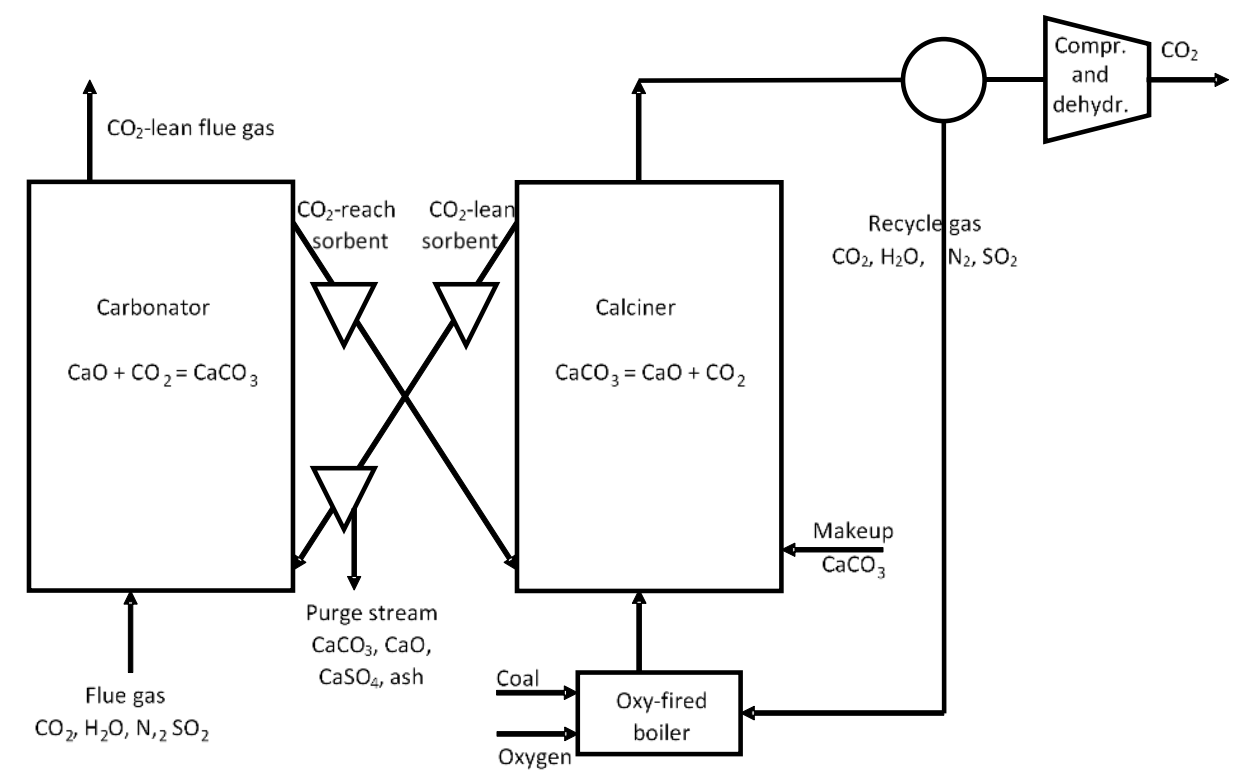

Figure 1. Diagram of the calcium looping (CaL) process for $\mathrm{CO}_{2}$ capture, according to [13].

The efficiency of $\mathrm{CO}_{2}$ capture (carbonation) by the sorbent and its regeneration (calcination) depends on the reaction kinetics, the sorbent grain size, its specific surface area, and the pore space characteristics. The cyclicity of the CaL process is accompanied by 
a decrease in the active surface of the sorbent particles due to the tight packing of $\mathrm{CaO}$ (regular system) in comparison to $\mathrm{CaCO}_{3}$ (trigonal system). Capture of $\mathrm{CO}_{2}$ by the $\mathrm{CaO}$ phase occurs in two stages. The first stage, in which the surface of the sorbent is covered with calcium carbonate, is characterized by a fast reaction rate and is strongly dependent on the partial pressure of $\mathrm{CO}_{2}[14,15]$. The second stage is slow-the contact of $\mathrm{CO}_{2}$ with the sorbent depends on diffusion through the $\mathrm{CaCO}_{3}$ coating. Therefore, $\mathrm{CaL}$ installations should be based on the use of the first stage [16]. The capture process can be described by, among others, the shrinking core model (SCM), in which both stages are included, as shown in Figure 2. According to this model, the reaction proceeds at a narrow front that moves into the solid particle. The reactant is completely converted as the front passes by [17].

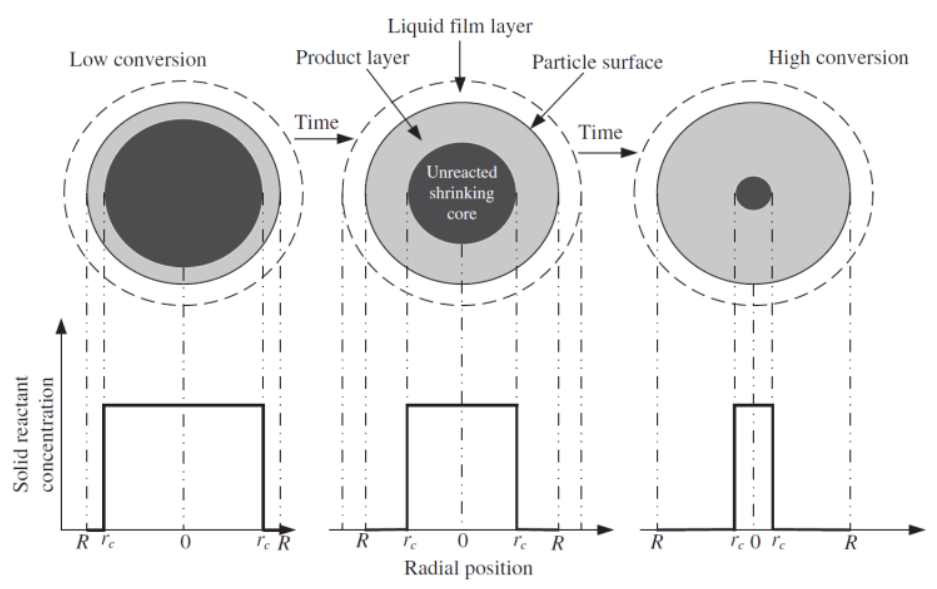

Figure 2. Schematic diagram of the shrinking core model (SCM), according to [17].

The conversion of sorbent can be expressed on the basis of mass change as follows:

$$
X=\left(\frac{m-m_{0}}{m_{0}}\right) \cdot \frac{M_{\mathrm{CaO}}}{M_{\mathrm{CO}_{2}}}
$$

where $m$ is the sorbent mass at the time $t, m_{0}$ is the initial mass of the sorbent, and $M_{C a O}$ and $\mathrm{M}_{\mathrm{CO} 2}$ are the molar masses of $\mathrm{CaO}$ and $\mathrm{CO}_{2}$.

According to [17], given the spherical shape of sorbent particles, the relationship of sorbent conversion with particle radius is given by the formula:

$$
1-X=\left(\frac{\text { volume of unreacted core }}{\text { total volume of particle }}\right)=\frac{\frac{4}{3} \pi r_{c}^{3}}{\frac{4}{3} \pi R^{3}}=\left(\frac{r_{c}}{R}\right)^{3}
$$

Let the time for complete conversion of a particle be $\tau(\mathrm{s})$, and $\mathrm{t}$ is the time of the carbonation reaction (s). Then, in terms of the fractional time for the carbonation reaction, the conversion of the sorbent is given by:

$$
X=1-\left(\frac{r_{c}}{R}\right)^{3}=\frac{t}{\tau} .
$$

Thus, we obtain the general relationship of time with the radius and with the conversion, and the progression of the chemical reaction in terms of the fractional conversion becomes:

$$
1-(1-X)^{\frac{1}{3}}=\frac{t}{\tau}
$$


while the progression of diffusion is:

$$
1-3(1-X)^{\frac{2}{3}}+2(1-X)=\frac{t}{\tau}
$$

\section{Materials and Methods}

In this work, rock samples representing the listed lithological types were studied as potential sorbents in the CaL process (Table 1).

Table 1. Samples studied as potential sorbents in the CaL process.

\begin{tabular}{|c|c|c|c|c|c|}
\hline Sample & Rock Type & Site/Age & Sample Mass [mg] & Mass Loss [\%] & $\mathrm{CaCO}_{3}[\%]$ \\
\hline 1 & limestone & Stramberk(Czechia)/Jurassic & 20.02 & 41.57 & 90.1 \\
\hline 2 & limestone & Podlesie (Poland)/Devonian & 19.58 & 39.00 & 84.5 \\
\hline 3 & limestone & Butkov (Slovakia)/Cretaceous & 20.32 & 31.81 & 68.9 \\
\hline 4 & bituminous limestone & Dębnik (Poland)/Devonian & 14.72 & 34.51 & 78.5 \\
\hline 5 & limestone & $\begin{array}{l}\text { Saint Anne Mountain } \\
\text { (Poland)/Triassic }\end{array}$ & 15.46 & 42.88 & 97.5 \\
\hline 6 & limestone & Gorazdze (Poland)/Triassic & 13.9 & 42.09 & 95.7 \\
\hline 7 & dolomite & Olkusz (Poland)/Triassic & 14.99 & 46.06 & $94.4^{1}$ \\
\hline 8 & marl & Cisownica (Poland)/Cretaceous & 15.09 & 29.75 & 67.7 \\
\hline 9 & basalt (nefelinite) & $\begin{array}{l}\text { Saint Anne Mountain } \\
\text { (Poland)/Tertiary }\end{array}$ & 14.55 & 1.92 & - \\
\hline 10 & magnesite & Braszowice (Poland)/Tertiary & 14.91 & 50.91 & $97.5^{2}$ \\
\hline 11 & serpentinite & $\begin{array}{l}\text { Jordanów (Poland)/older than } \\
\text { UpperDevonian }\end{array}$ & 14.46 & 26.97 & - \\
\hline
\end{tabular}

$1 \% \mathrm{CaMg}\left(\mathrm{CO}_{3}\right)_{2},{ }^{2} \% \mathrm{MgCO}_{3}$.

The rock samples were mechanically ground using a PM 100 CM ball mill (Retsch, Haan, Germany) to a fraction of less than $0.08 \mathrm{~mm} . \mathrm{CO}_{2}$ sorption studies were carried out on the STA 449 F3 Jupiter (Netzsch, Selb, Germany) apparatus. Samples weighing about $15 \mathrm{mg}$ were placed in an $\mathrm{Al}_{2} \mathrm{O}_{3}$ crucible. First, the mass change of the analyzed samples was measured (Table 1); this allowed the determination of the share of calcite (or dolomite) in carbonate rocks. Measurements were made in $\mathrm{N}_{2}$ atmosphere at a temperature of up to $1030{ }^{\circ} \mathrm{C}$ and a heating rate of $10 \mathrm{~K} / \mathrm{min}$. Next, the simulation of the CaL process was carried out using a temperature program (Figure 3), which consisted in heating (calcination) of the primary sample from a temperature of $40{ }^{\circ} \mathrm{C}$ to about $900{ }^{\circ} \mathrm{C}$ at a rate of $20^{\circ} \mathrm{C} / \mathrm{min}$ in a $\mathrm{N}_{2}$ atmosphere with a flow of $25 \mathrm{~mL} / \mathrm{min}$. Then, a $10 \mathrm{~min}$ isothermal section was introduced, and the temperature was lowered to about $650{ }^{\circ} \mathrm{C}$. Then, the carbonation process was carried out, keeping the sample at this temperature for $10 \mathrm{~min}$ with the attached $\mathrm{CO}_{2}$ flow at the rate of $25 \mathrm{~mL} / \mathrm{min}$. The test was carried out in 10 cycles of alternating calcination and carbonation. During the measurements, changes in the mass of the sample over time (TGA) and heat flow (DSC) were recorded.

In this work, we the tested raw sorbents (unmodified) as well as selected limestone sorbents that were thermally modified by pre-heating the sample for one hour at $1000{ }^{\circ} \mathrm{C}$ in $100 \% \mathrm{~N}_{2}$ atmosphere. 


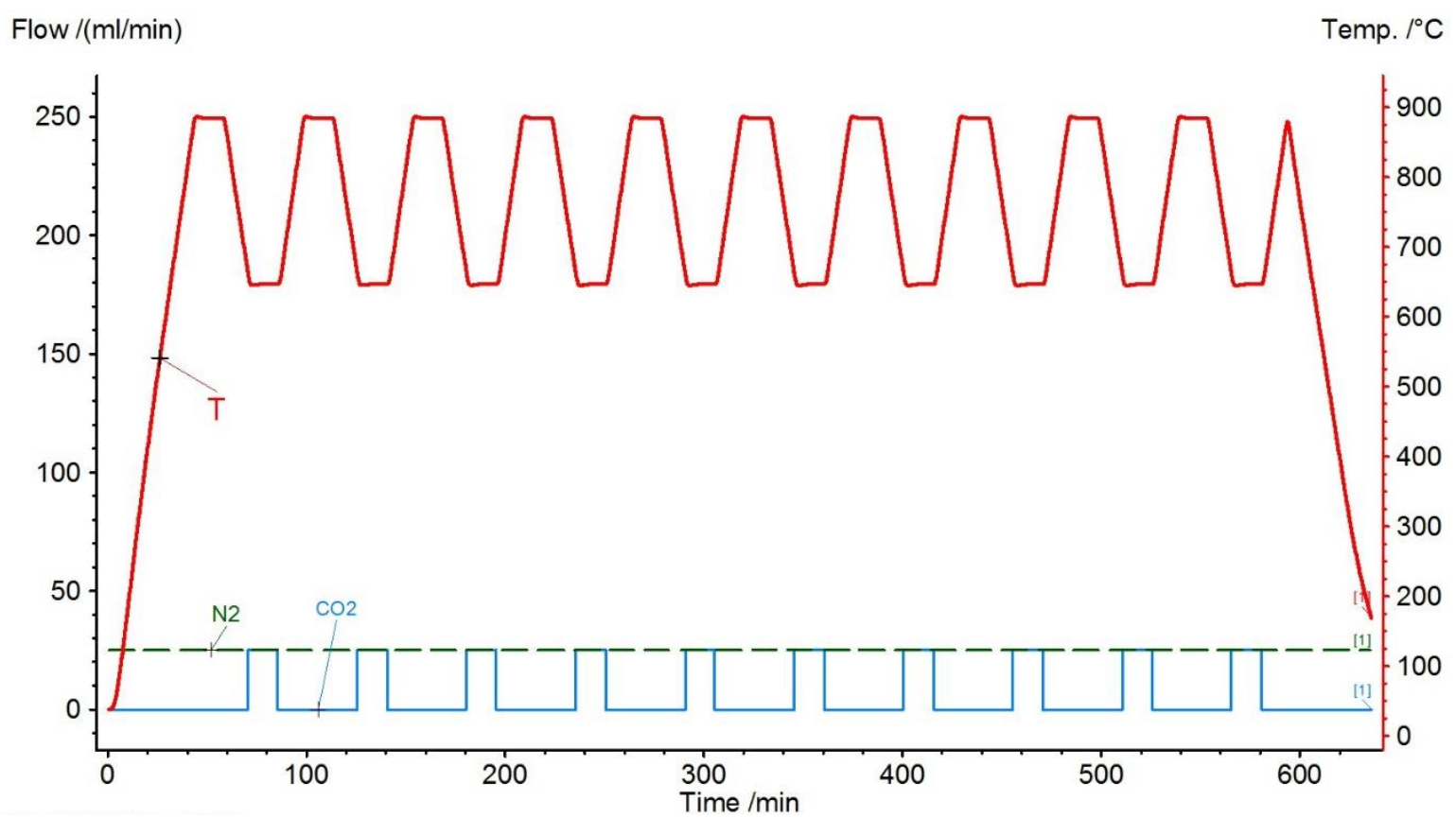

Figure 3. Example of a temperature program sequence (purple), and gas flow (green dashed line $-\mathrm{N}_{2}$, blue solid line $-\mathrm{CO}_{2}$ ).

\section{Results}

\subsection{Raw Sorbents}

\subsubsection{Dolomite}

The simulation of the CaL process for dolomite showed an initial weight loss of the sorbent (calcination) amounting to $45.06 \%$ of its weight (Figure 4), which means that the sorbent was composed of almost pure $\mathrm{CaMg}\left(\mathrm{CO}_{3}\right)_{2}$. The dolomite derivatogram reveals that two reactions registered on the DSC curve as two adjacent endothermic effects at 740 and $870{ }^{\circ} \mathrm{C}$. The first is responsible for the $\mathrm{CO}_{2}$ release from $\mathrm{MgCO}_{3}$, and the second from $\mathrm{CaCO}_{3}$; the sample mass losses are 23.59 and $21.47 \%$, respectively. During carbonation, the $\mathrm{CO}_{2}$ capture was obtained, causing the sample mass changes in the range from $18.77 \%$ (first cycle) to $10.30 \%$ (10th cycle) (Figure 5). The gas capture efficiency decreased with increasing number of $\mathrm{CaL}$ cycles, which may be related to the decreasing active surface of the sorbent due to sintering.

It is worth noting that the carbonation process was not completed within the assumed time of $10 \mathrm{~min}$. This is evident in the sample mass change (TGA) graph, which shows the rapid rise (reaction step-line 1) smoothly moving through the transition (line 2) towards the diffusion step (line 3). According to the SCM model, such effects are connected with the increasing thickness of the $\mathrm{CaCO}_{3}$ layer surrounding the unreacted $\mathrm{CaO}$ core. However, this last step was not fully completed, as shown by the line 3 , which is tangent to a portion of the mass loss curve still deviates from the horizontal position. This means that in the case of dolomite sorbent, carbonation could be carried out for a longer time than assumed in the analyzed simulation. This is justified by the observation of the occurrence of a segment typical for the diffusion that was visible at the time of about $10 \mathrm{~min}$ after closing the $\mathrm{CO}_{2}$ flux to the reaction chamber of the furnace, when the atmosphere was not fully replaced with the protective gas $\left(\mathrm{N}_{2}\right)$. In this case, the extension of the carbonation time may be associated with a potential reduction in the economics of the capture process, as the recorded increase in uptake by diffusion was only $0.29 \%$ in the first cycle, and in the next, it was about $1 \%$ of the sorbent sample mass (Figure 5). This issue would require further tests with extended carbonation time in order to calculate the amount of $\mathrm{CO}_{2}$ bound by the sorbent through the diffusion process. 


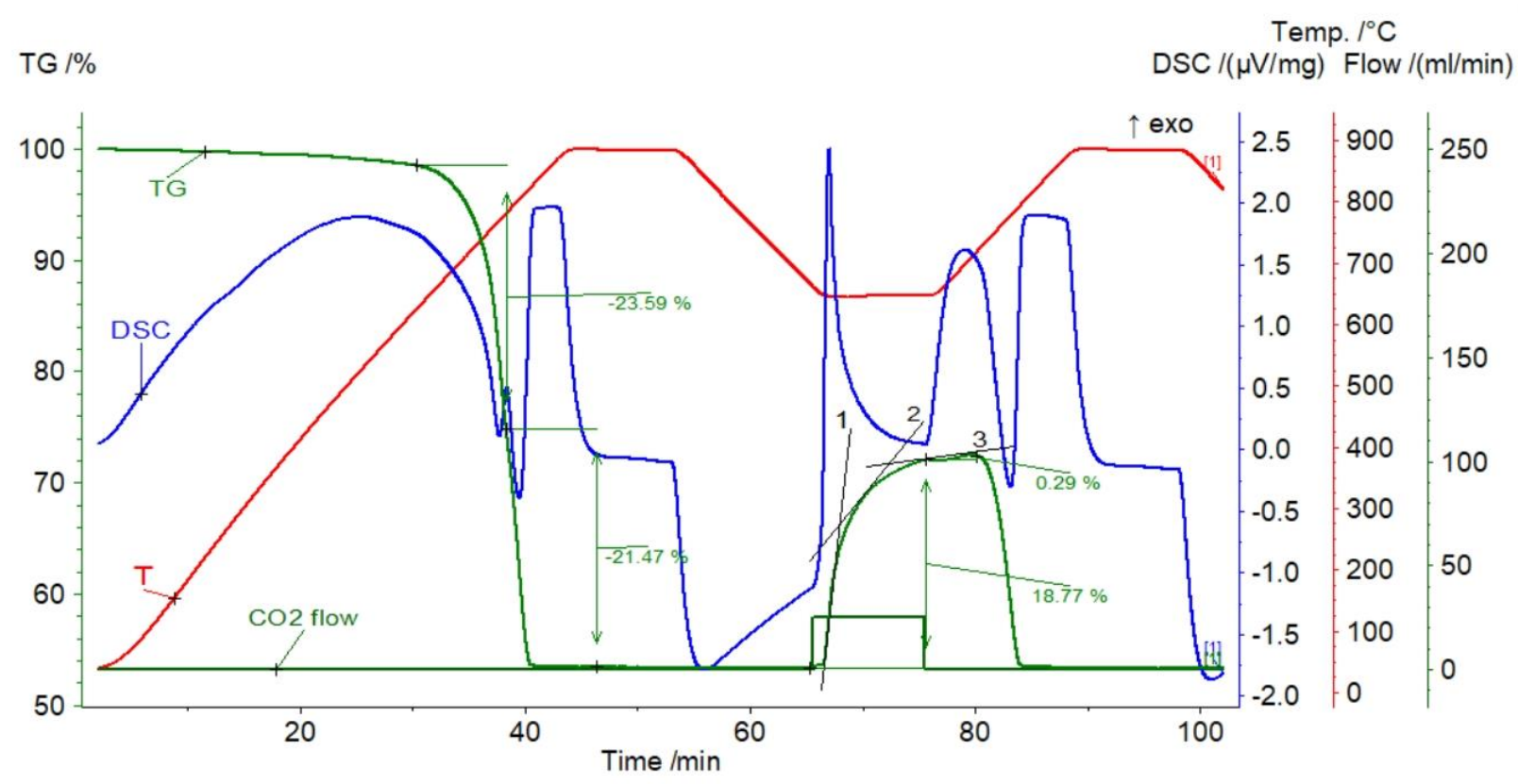

Figure 4. TGA and DSC curves for dolomite.

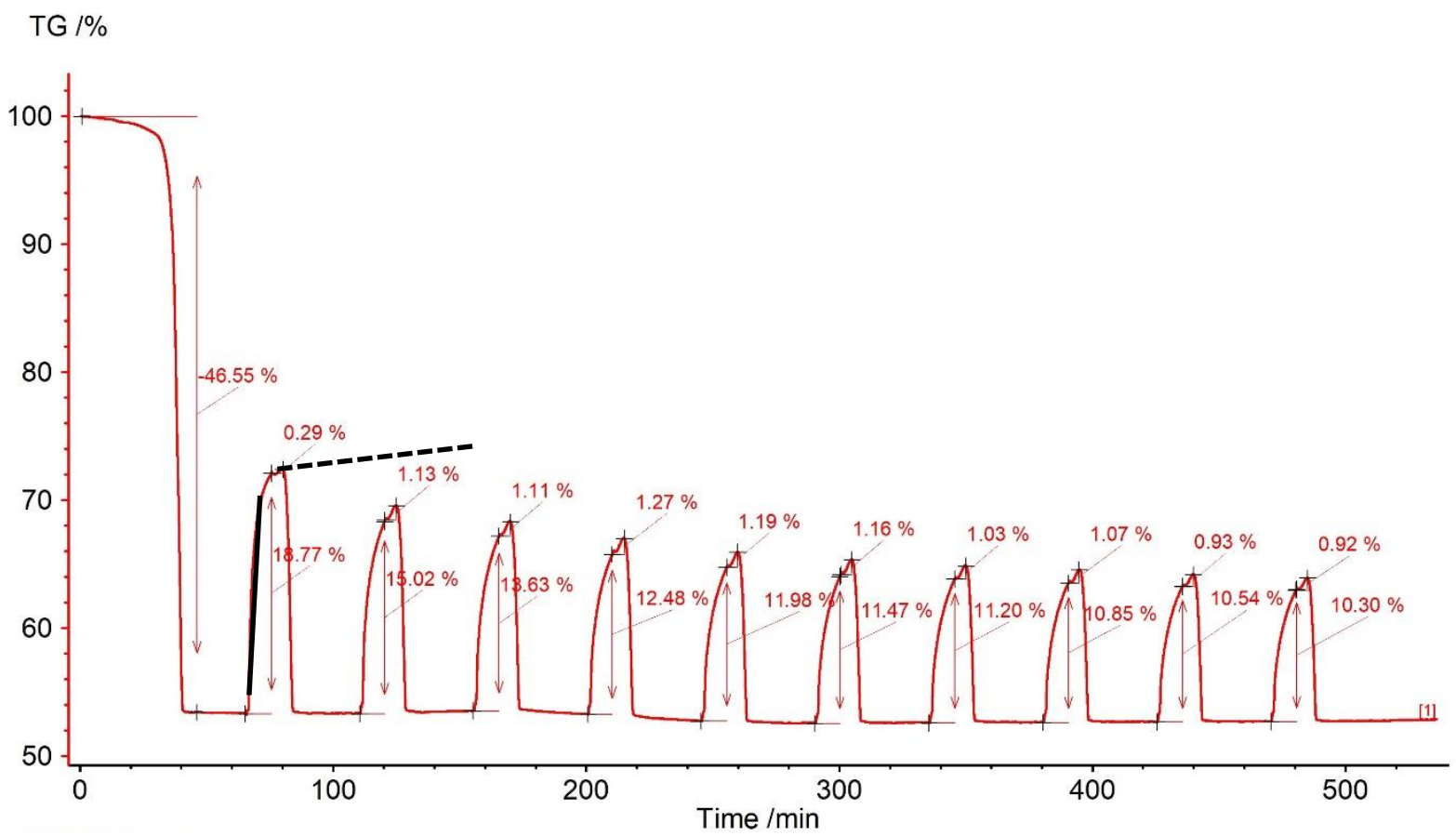

Figure 5. Relative mass changes for dolomite in the CaL process (the solid black line marks the section of the surface reaction, and the dashed line marks the section possibly corresponding to diffusion).

\subsubsection{Saint Anne Mountain Limestone}

The initial weight loss of the sorbent was observed (dehydration and calcination) to amount to $42.89 \%$ of its weight (Figure 6), which means that the sorbent was composed of almost pure calcium carbonate. Carbonation caused the sample mass changes in the range from $30.49 \%$ (first cycle) to $12.42 \%$ (10th cycle) (Figure 7 ). 


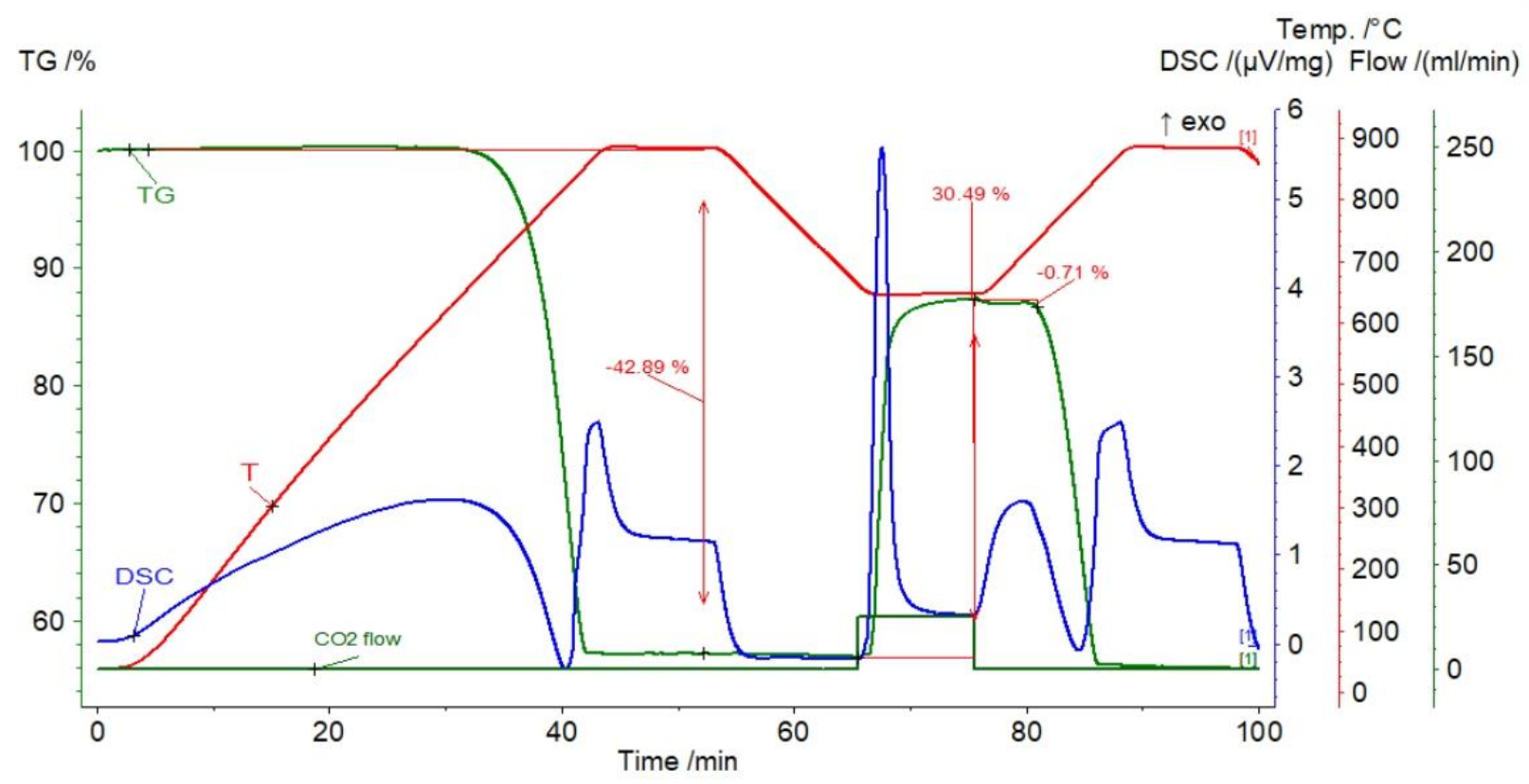

Figure 6. TGA and DSC curves for limestone from Saint Anne Mountain.

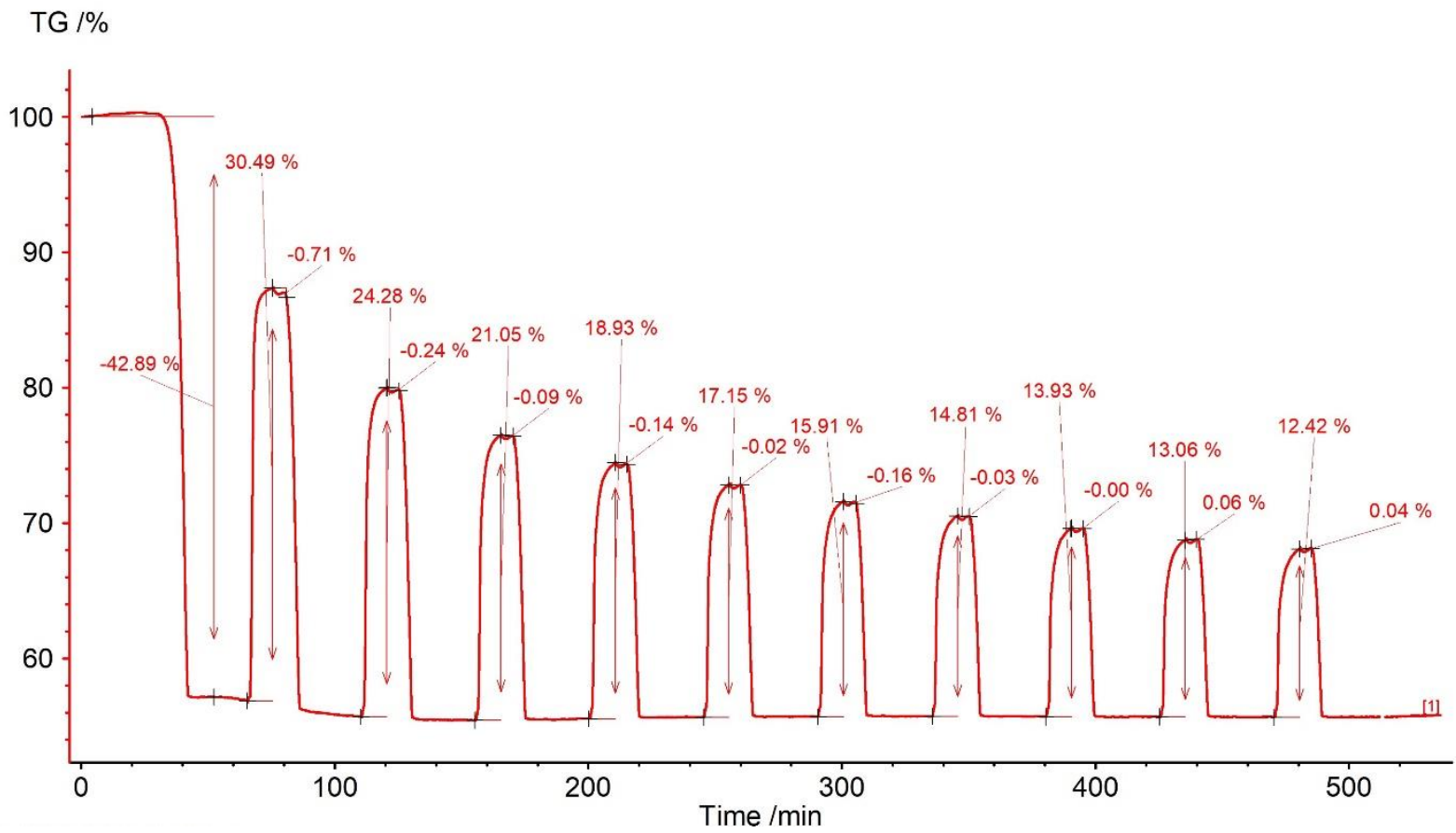

Figure 7. Relative mass changes for the limestone from Saint Anne Mountain.

The gas capture efficiency clearly decreased after the first cycle - to $24.28 \%$ - which may be related to the reduction in the active sorbent surface due to sintering. In subsequent cycles, this decline showed a downward trend. It should be noted that the reaction segment (visible as a steep mass increase) was shortened more and more in subsequent steps. At the same time, the elongation of the transition section was noticeable-this proves the increasing role of diffusion and confirms the sintering phenomenon. At the end of the assumed carbonation stage, a slightly inclined section of the sample mass increase was formed, which proves the diffusion process at that time (Figure 6). In addition, within 
about 5 min after closing the $\mathrm{CO}_{2}$ supply, small, unsystematic fluctuations in the mass of the sample are revealed (from $-0.71 \%$ to $+0.06 \%$ ), followed by rapid calcination.

\subsubsection{Marl}

A decrease in the weight of the sorbent was observed, amounting to $29.75 \%$, of which about $4 \%$ corresponded to dehydration and dehydroxylation of clay minerals, and the remaining $25.73 \%$ corresponded to carbonate decomposition (Figure 8 ). Carbonation caused the sample mass changes within the range from $3.52 \%$ (first cycle) to $1.67 \%$ (10th cycle) (Figure 9). The efficiency of $\mathrm{CO}_{2}$ gas uptake decreased at a decreasing rate, which may be related to the reduction in the active surface of the sorbent due to sintering (Figure 12). The reaction segment was shortened in successive stages, and instead, the elongation of the transition section became noticeable. This proves the increasing role of diffusion and confirms the sintering phenomenon. Within about $5 \mathrm{~min}$ after closing the $\mathrm{CO}_{2}$ valve, slight fluctuations in the mass of the sample were revealed, with a clearly decreasing character with subsequent cycles. They were followed by rapid calcination.

\subsubsection{Nephelinite}

The initial weight loss of the sorbent (poorly marked dehydration and calcination) was observed, amounting to $1.90 \%$ of its weight (Figure 10) and showing a small, potential share of carbonates (most likely filling cracks or voids formed during degassing of basaltic lava). During carbonation, the gas capture efficiency showed no systematic variability, and in most cycles, it ranged from 0.63 to $0.68 \%$. In only the first cycle, the reaction section (steep mass increase fragment) was short, followed by the diffusion section. In subsequent stages, the reaction segments were higher. They were followed by slight fluctuations in mass, lasting until the end of the assumed carbonation stage.

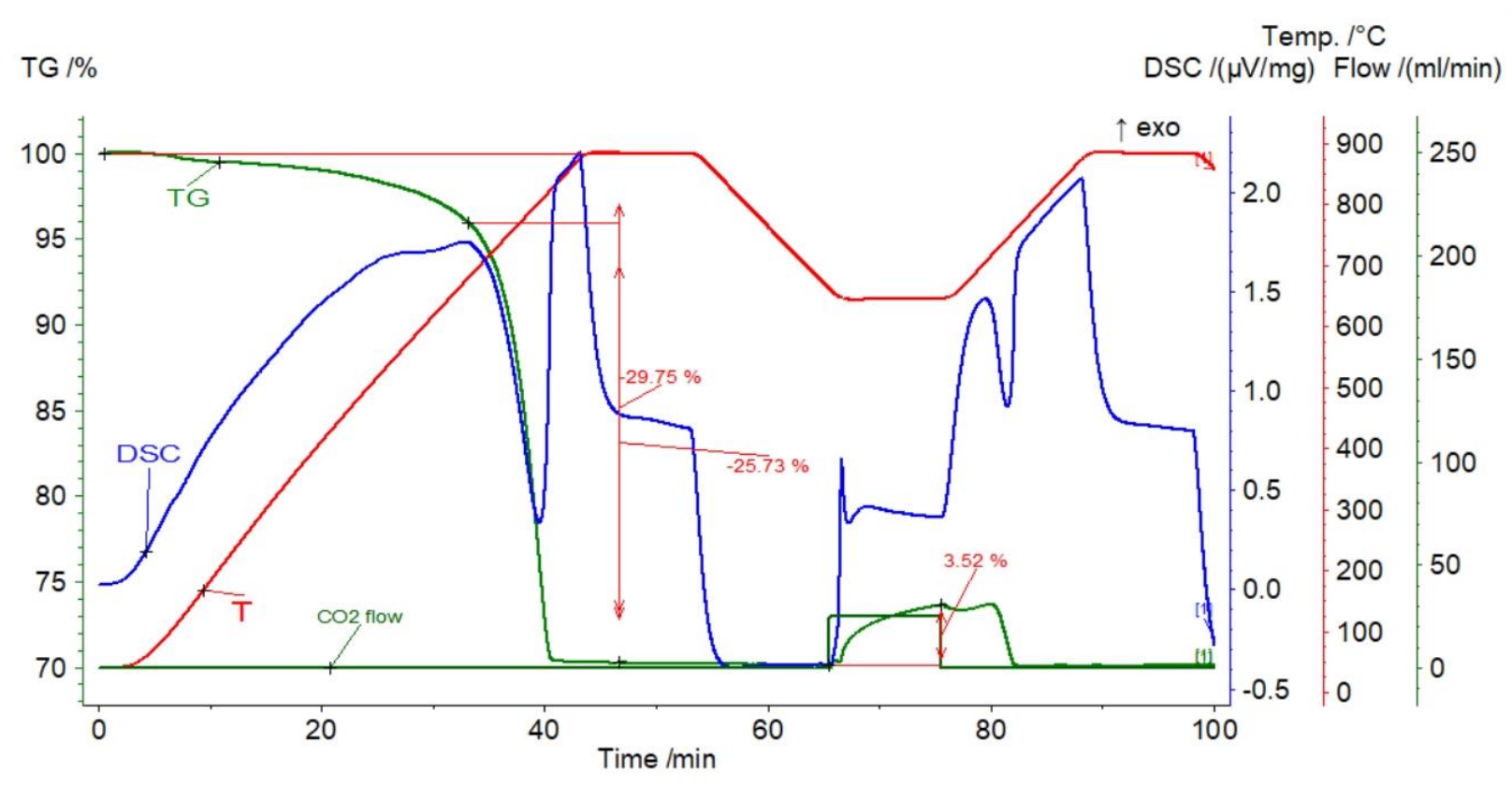

Figure 8. TGA and DSC curves for marl. 


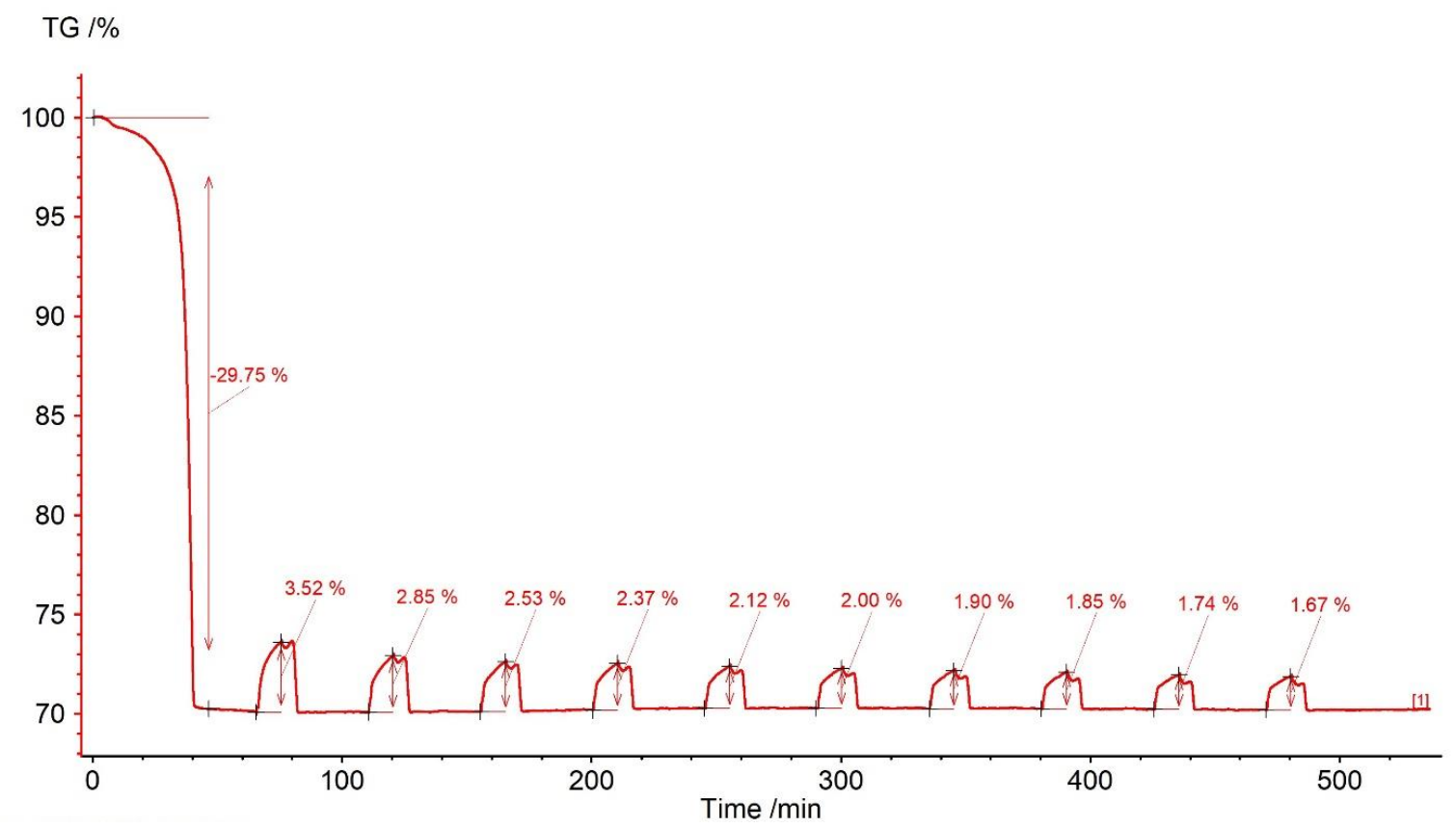

Figure 9. Relative mass changes for the marl.

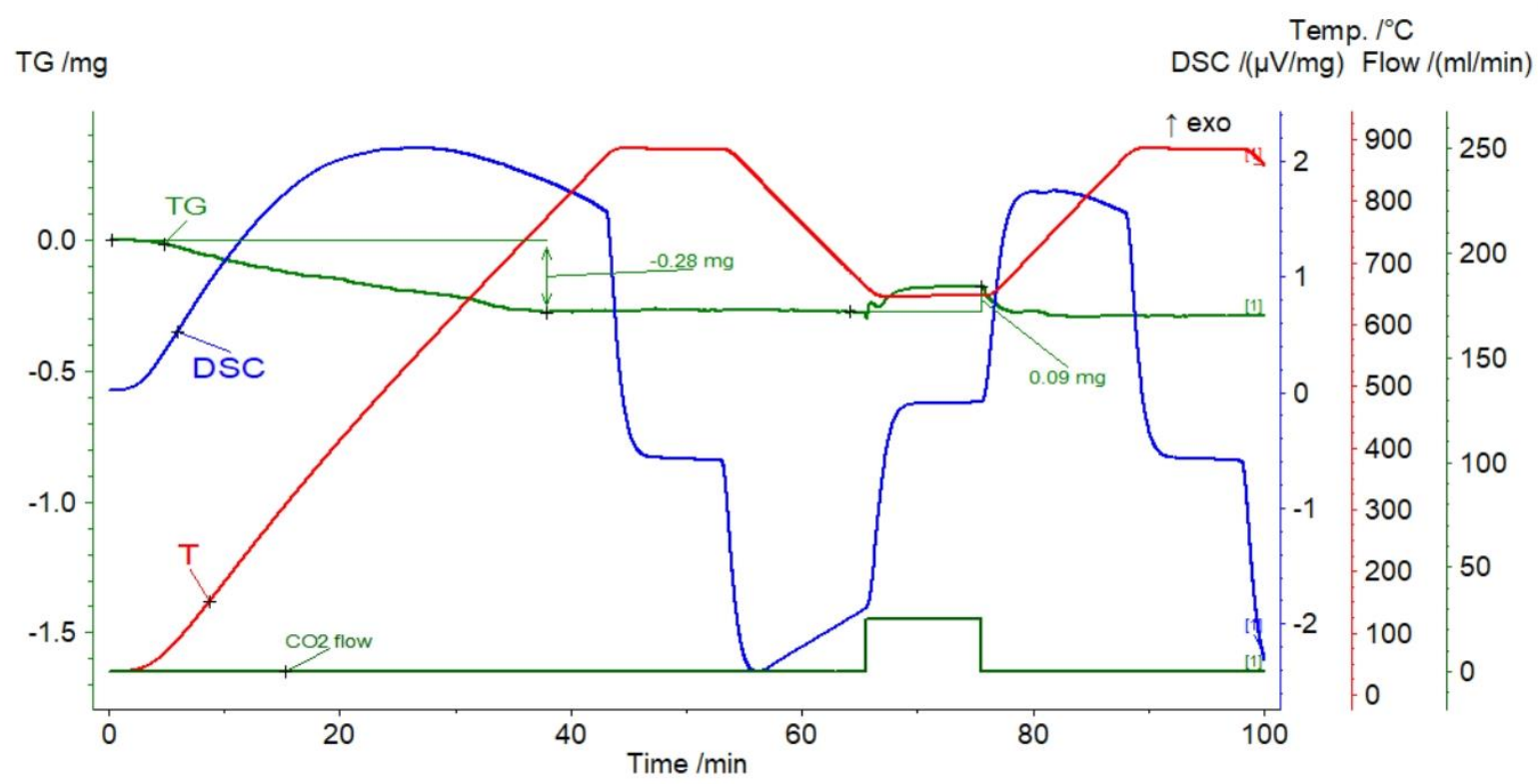

Figure 10. TGA and DSC curves for nephelinite.

\subsubsection{Magnesite}

The significant initial weight loss of the sorbent amounted to $50.92 \%$ of its weight (Figure 11), which proves the negligible potential contributions of other carbonates. The gas capture efficiency showed a decreasing trend, burdened with a non-systematic component, and ranged from $0.85 \%$ (cycle 1 ) to $0.72 \%$ (cycle 10). As in the case of the previously described nephelinite, in only the first cycle, the reaction section was short, followed by the diffusion process. In the next stages, the reaction segments were higher. Fluctuations in mass lasted until the end of the carbonation stage, and were followed by relatively slow calcination. 


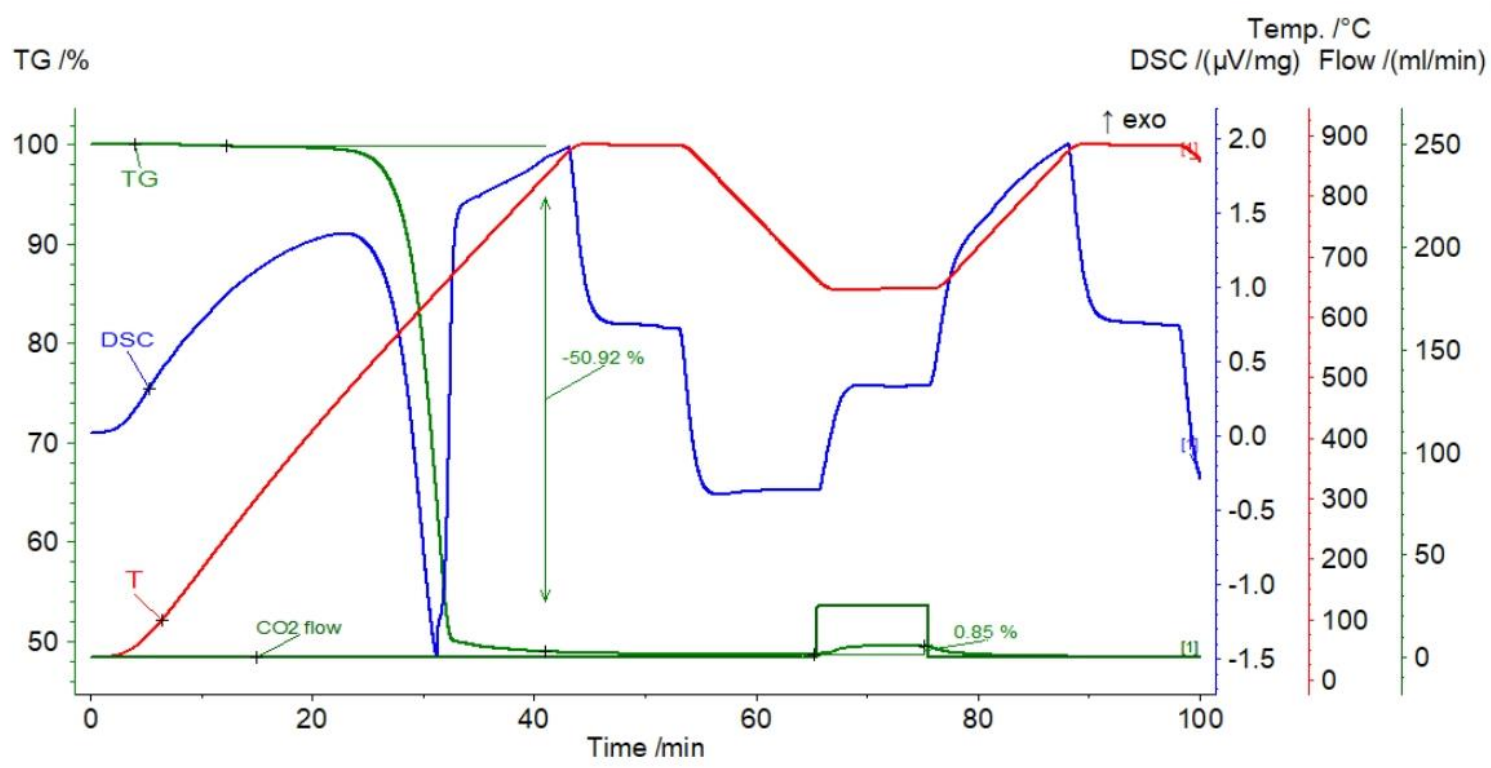

Figure 11. TGA and DSC curves for magnesite.

\subsubsection{Serpentinite}

The result of the DTA-TG analysis of serpentine sample is shown in Figure 12. Two endothermic peaks were found at temperatures of 623.1 and $701.9{ }^{\circ} \mathrm{C}$ due to the release of structural water. At a temperature of $834.1^{\circ} \mathrm{C}$, a large exothermic peak was visible, which represents the destruction of the serpentine crystalline structure and the formation of forsterite, enstatite, and clinoenstatite. For temperatures higher than $750{ }^{\circ} \mathrm{C}$, the TGA analysis showed no significant weight variation. During carbonation, the sample mass changes reached from $1.42 \%$ (first cycle) to $0.95 \%$ (10th cycle). The efficiency of gas capture decreased at a decreasing rate. The reaction segment was shortened in successive stages, while the diffusion segment became more apparent, which confirms the sintering of the sample. About $5 \mathrm{~min}$ after the $\mathrm{CO}_{2}$ shut off, there was a slight decrease in the mass of the sample-typical for the first-order reaction-followed by a sharp but slight weight loss due to calcination.

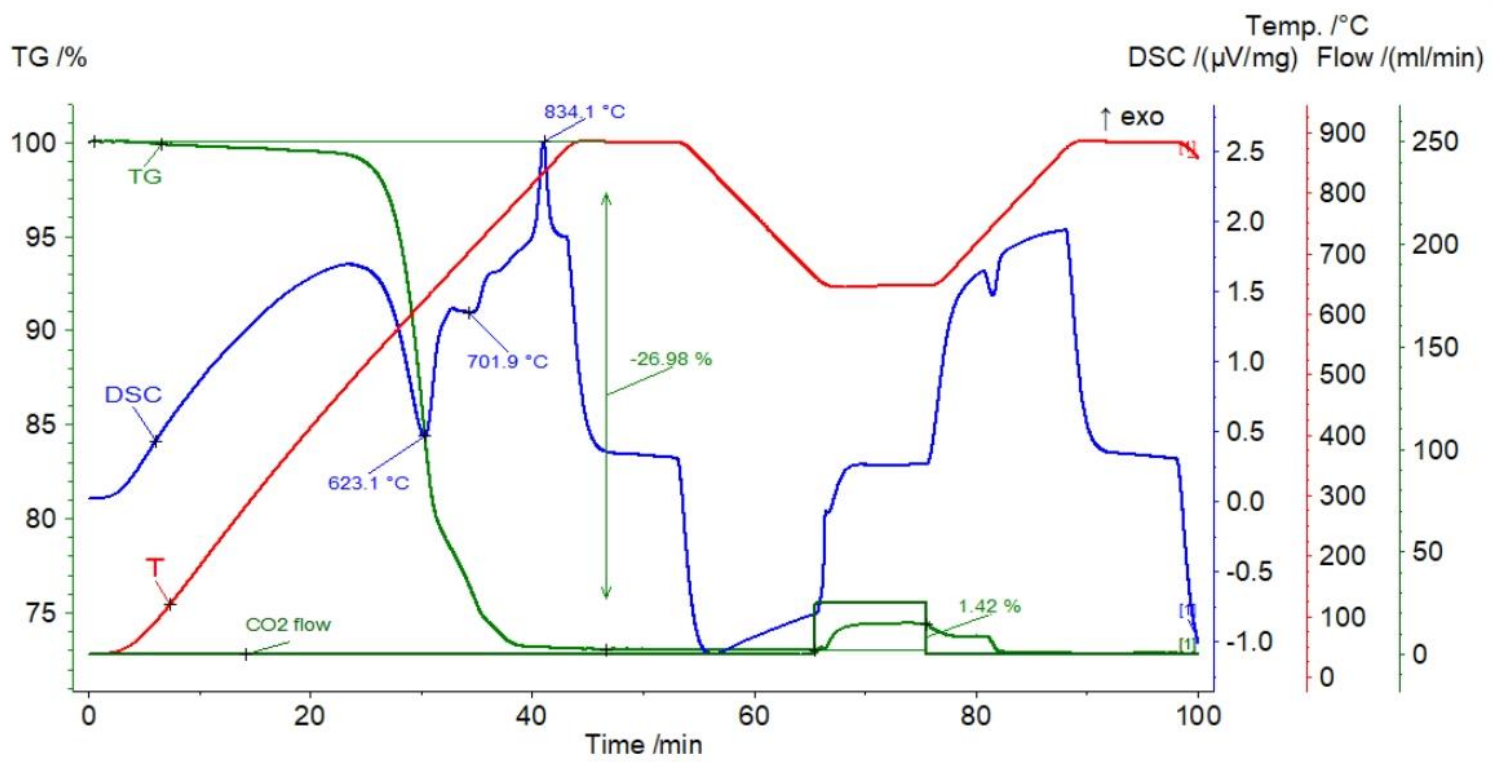

Figure 12. TGA and DSC curves for serpentinite. 


\subsection{Thermal Pretreatment of Sorbents}

Calcium sorbents are characterized by a decreasing activity of capturing $\mathrm{CO}_{2}$ in each subsequent carbonation cycle. After approximately one hundred cycles, the asymptotically decreasing sorbent yield ranges from 7 to $15 \%$ for a $10 \mathrm{~min}$ carbonation time. It is believed that this is the result of changes in the sorbent's morphology, during which its specific surface area decreases and the micropores disappear. In order to improve the activity of sorbents, the following enhancement techniques are used:

- Doping - aimed at postponing or avoiding sintering of sorbent in order to moderate sintering and abrasion of the sorbent (e.g., $[18,19])$. The effectiveness of doping depends on the concentration of the substrate used. Too low of a concentration will have no effect, while too high of a concentration may block the pores [12,20];

- Chemical treatment-to obtain a better sintering performance and more favorable pore area (e.g., $[21,22])$. Although the chemical treatment presents reactivity benefits, it has two drawbacks: the cost and availability of the acid and the marginal increase in $\mathrm{CO}_{2}$ uptake [23],

- Thermal pretreatment-to improve the conversion of $\mathrm{CaO}$ in long series of cycles and to stabilize the sorption capacity (e.g., [24,25]).

Research performed by Manovic and Anthony [25] and Manovic et al. [26] demonstrated that thermal pre-treatment could be an important method of improving conversion of $\mathrm{CaO}$ over long series of cycles. Such a phenomenon might be explained by a theory proposed by Lysikov et al. [27] and developed by Manovic and Anthony [25], according to which the repetitive carbonation/calcination cycles enhance the formation of a skeleton of interconnected $\mathrm{CaO}$. This skeleton acts as the outer layer of the reactive $\mathrm{CaO}$ layer and stabilizes the sorption capacity.

The tests by Manovic and Anthony [25] showed that the particles were strongly sintered and that carbonization occurred on the surface of the solid particle. The pretreatment resulted in the formation of an internal skeleton of the sorbent particles and protection of their integrity. When the sorbents are preheated, after the decomposition of $\mathrm{CaCO}_{3}$, ion diffusion continues and stabilizes the skeleton, which, due to its porous structure, is able to maintain significant carbonation (Figure 13).

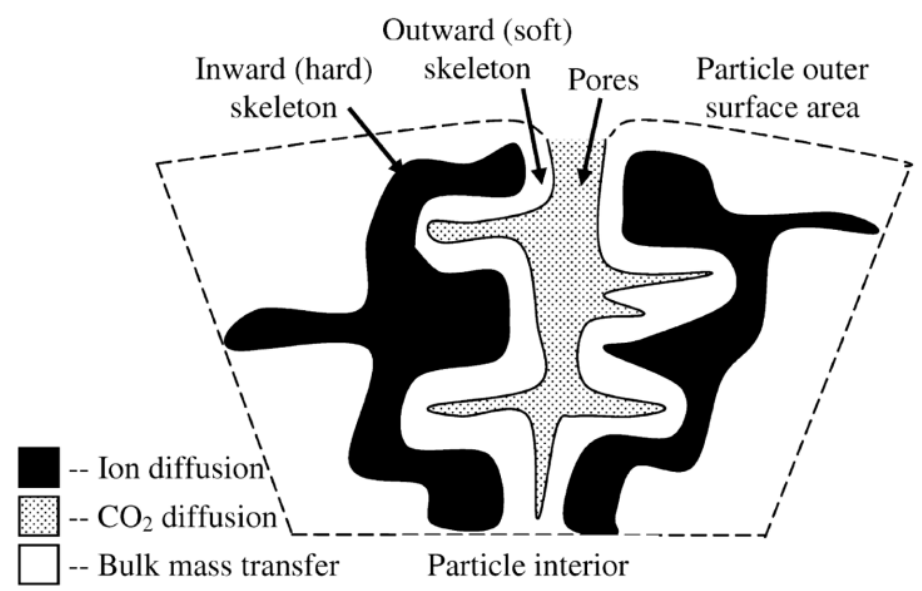

Figure 13. Schematic representation of the pore-skeleton model [25].

Manovic and Anthony [20] studied the improvement of sorbent properties (Kelly Rock limestone) with $54.39 \% \mathrm{CaO}$ content and loss on ignition (44.20\%) through steam reactivation, thermal pre-treatment, and addition of calcium-aluminate-based pellets. The most promising results were obtained for powdered Kelly Rock limestone samples $(<50 \mu \mathrm{m})$. For the preheating temperatures of $1000^{\circ} \mathrm{C}$, the sorbent was self-reactivated for the next 30 carbonation cycles. The highest conversions were obtained at $1000{ }^{\circ} \mathrm{C}$, for which $49 \%$ conversion was achieved in the last cycle, with an average value of $\sim 45 \%$ for 30 cycles. 
Lower conversion values were obtained for samples pretreated at 1100 and $1200{ }^{\circ} \mathrm{C}$. However, taking into account the self-reactivation effect, these results may also be promising, especially since heating the sorbent at these temperatures (in combination with granulation) gives better mechanical properties that could prevent its undesirable attrition. Assuming that the pretreatment time is an important parameter, a $6 \mathrm{~h}$ thermal activation study was also carried out on Kelly Rock powdered samples at temperatures of $900-1100{ }^{\circ} \mathrm{C}$. It was confirmed that the pretreatment time influences the properties of the sorbent, and that shorter thermal treatment times can positively influence the effectiveness of the sorbent [25].

In this work, based on the results of the preliminary tests, three limestone samples from Stramberk (Czechia), Podlesie (Poland), and Butkov (Slovakia) (Table 1) were selected for further testing. They were characterized by high, medium, and the lowest weight loss, respectively. The tested sorbents were thermally modified by pre-heating the sample for one hour at $1000{ }^{\circ} \mathrm{C}$ in $100 \% \mathrm{~N}_{2}$ atmosphere. A further research cycle was carried out according to the procedure described earlier.

The effect of thermal pretreatment is presented for the example of limestone from Stramberk (Czechia) (Figure 14A,B). During the carbonation of the raw sample, $\mathrm{CO}_{2}$ capture was achieved, causing the sample mass to change within a range from $31.36 \%$ (first cycle) to $13.68 \%$ (10th cycle). The gas capture efficiency decreased with increasing number of CaL cycles. After the first cycle, the gas uptake efficiency decreased to $25.36 \%$, which may be due to the reduction of the active sorbent surface due to sintering. It is noticeable that the reaction time (visible as a steep section of the mass increase) got shorter in subsequent cycles. Simultaneously with the reduction of the reaction section, the extension of the transition section was noticeable, which proves the increasing role of diffusion and confirms the phenomenon of sintering of the sample.

It is noteworthy that, within the assumed time of $10 \mathrm{~min}$, the carbonation process was not completed. This is evident in the sample mass change graph, which shows a sharp rise (reaction stage) moving smoothly (transition stage) towards the diffusion stage. The latter, however, is not observed (no element approaching the horizontal line, mass growth curve). This means that in the case of the Stramberk limestone, carbonation could be carried out for a longer time than assumed in the analyzed simulation. The extension of the carbonation time in this case may be associated with a potential reduction in the economics of the capture process. This issue would require further tests with extended carbonation time in order to calculate the amount of $\mathrm{CO}_{2}$ bound by the sorbent through the diffusion process.

The comparison of the relative mass changes for Stramberk limestone without modification and thermally pretreated samples proves that the end of the reaction stage occurs at a similar temperature-around $644.5^{\circ} \mathrm{C}$ (Figure 15). The calcination time varies, however, and is shorter for the unmodified sorbent, which is related to the lower content of $\mathrm{CO}_{2}$ blocked in this sample. 

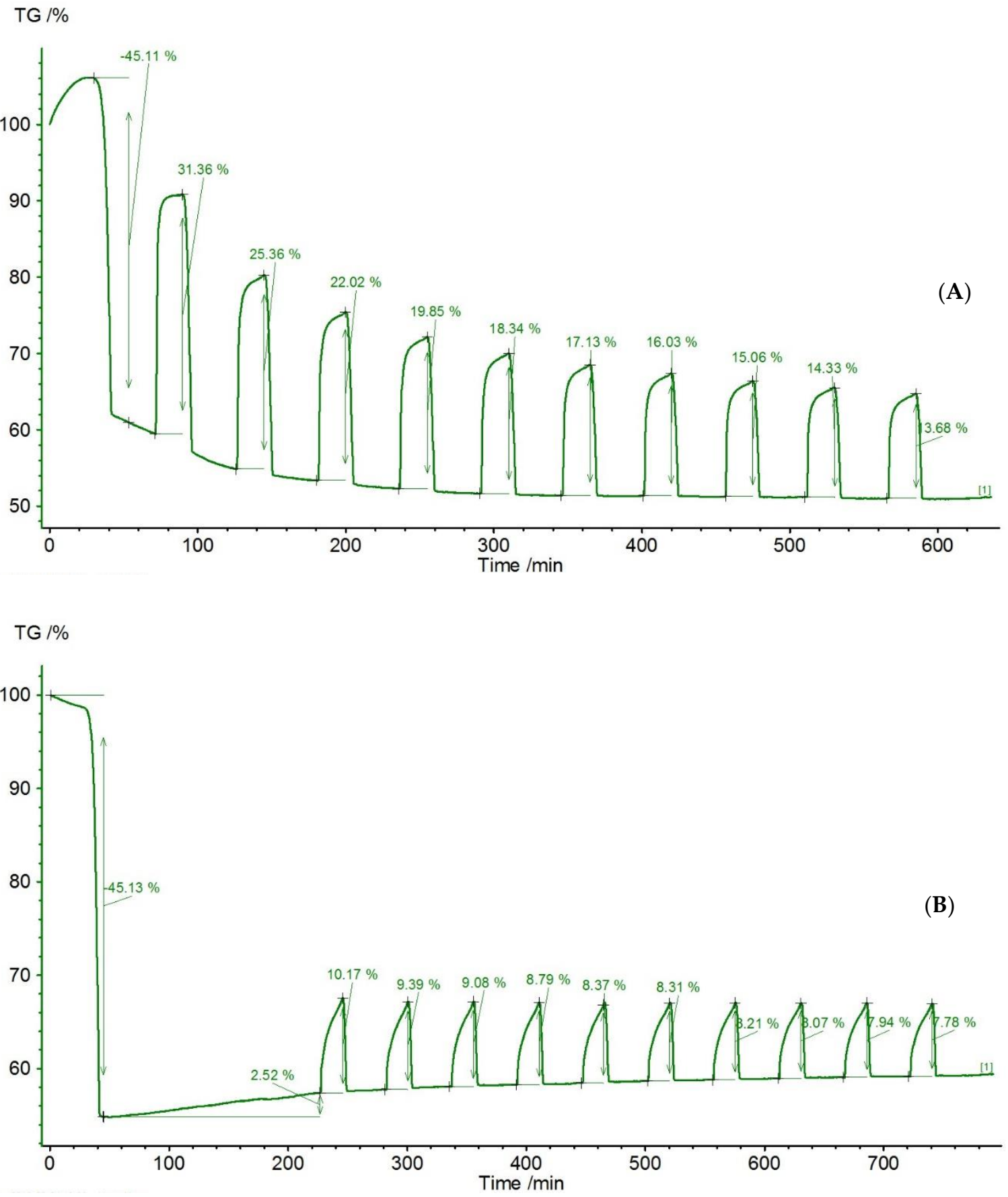

Figure 14. Relative mass changes for Stramberk limestone: (A) unmodified; (B) thermally pretreated for $1 \mathrm{~h}$ at $1000{ }^{\circ} \mathrm{C}$. 


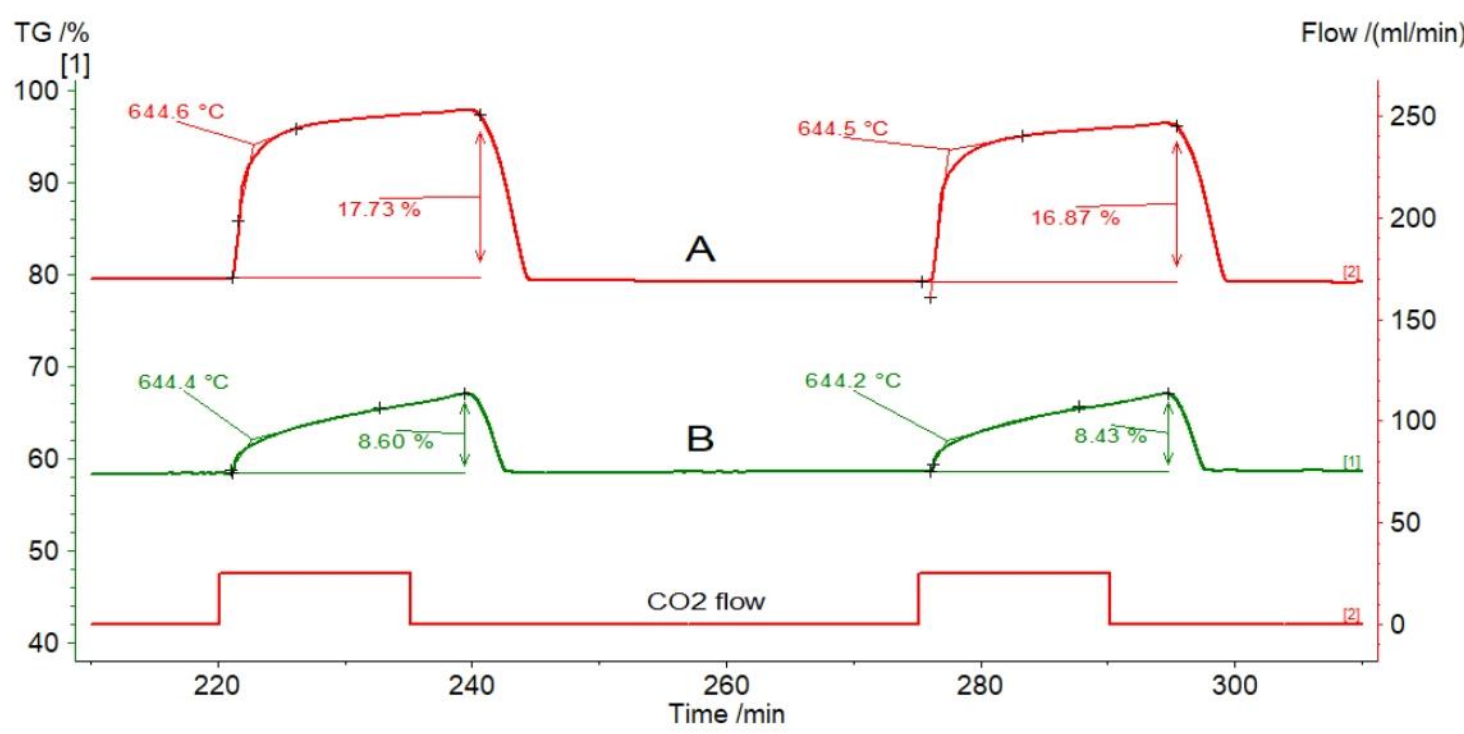

Figure 15. Relative mass changes for Stramberk limestone at the fifth and sixth calcium looping cycles: (A) without modification; (B) pretreated for $1 \mathrm{~h}$ at $1000^{\circ} \mathrm{C}$.

\section{Discussion}

The CaL simulations showed different degrees of conversion for the tested rock sorbents (Figures 16 and 17). As expected, they were the highest for carbonate rocks (except for bituminous limestone); intermediate values were found for marl and bituminous limestone, and the values were lower by an order of magnitude for the remaining sorbents: magnesite and serpentinite. The lowest degree of conversion was determined for basalt.

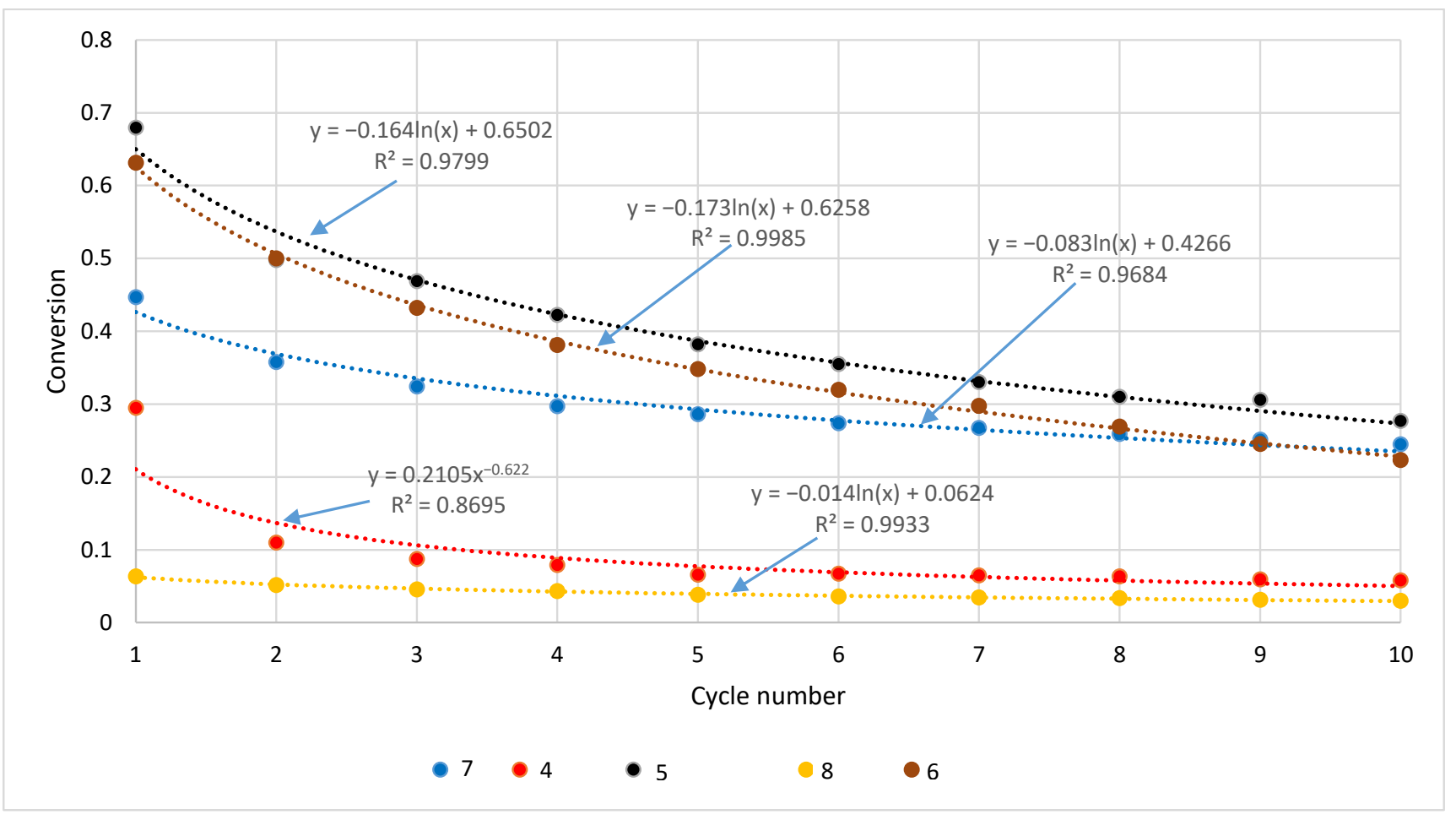

Figure 16. The conversion of carbonate rocks in the CaL process. 


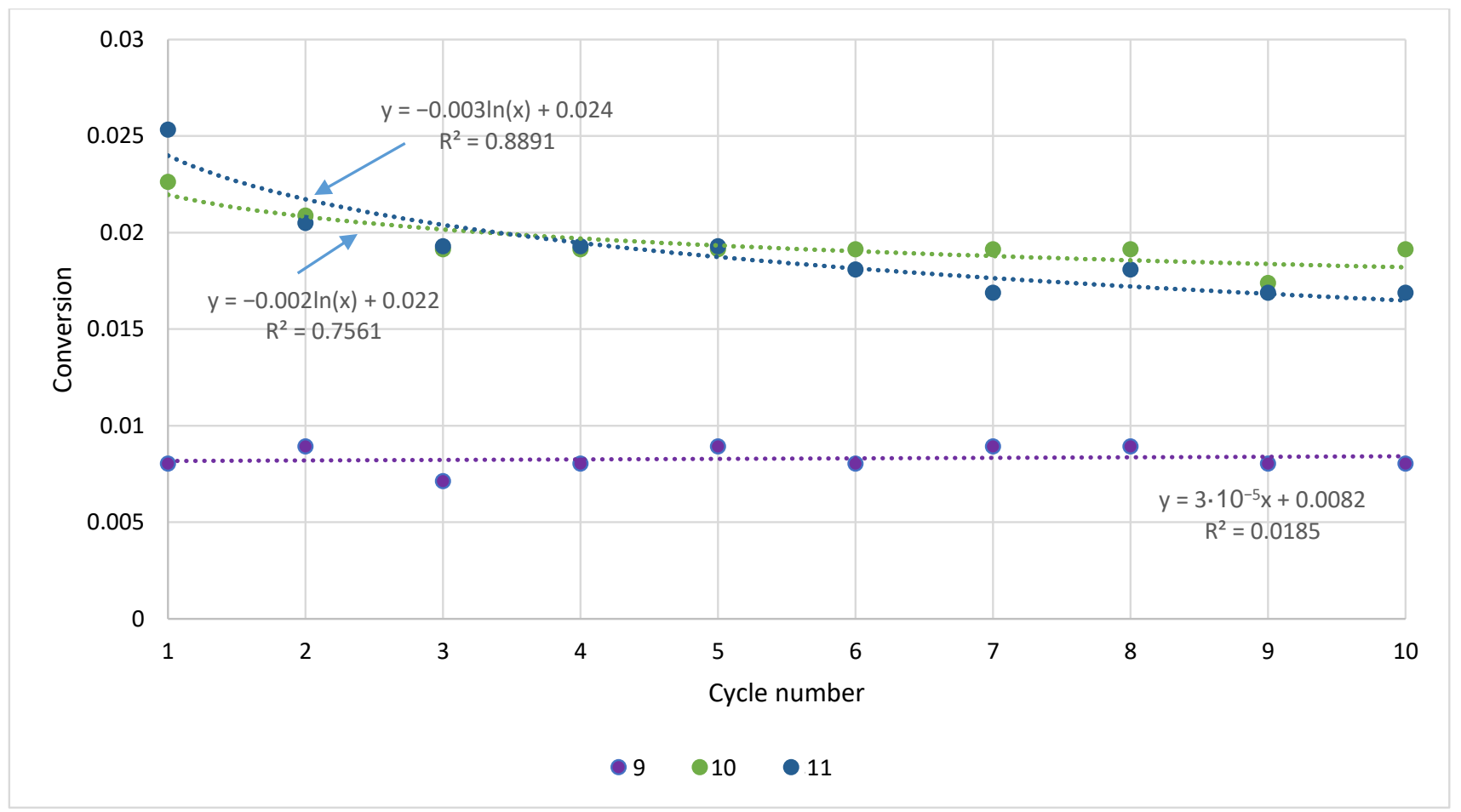

Figure 17. The conversion of magnesite and non-carbonate rocks in the CaL process.

The decrease in the conversion rate with subsequent CaL cycles was most pronounced for the sorbents with the highest values of this parameter, again with the exception of bituminous limestone (for which a significant decrease was noted between the first and second cycles; Figure 16). In the case of basalt, there were no significant changes in the conversion rate during the simulated cycles.

From the standpoint of the efficiency of the CaL process, an important indicator is the parameter called "cumulative carbonation relative to the initial mass of the sorbent", which, for the 10 analyzed cycles $(n=10)$, could be defined as the degree of carbonation for $n$ cycles.

It represents the multiplicity of the captured $\mathrm{CO}_{2}$ relative to the initial sorbent mass. In the course of the analyzed cycles, the cumulative carbonation shows regularities that are similar to the degree of conversion (Figures 18 and 19). This parameter, exceeding 1.0, was also the highest for carbonate rocks (limestones: Stramberk-1.93, Saint Anne Mountain -1.81, Gorazdze-1.65, Podlesie-1.62, and dolomite of Olkusz-1.26); values that were lower by an order of magnitude were achieved for marl, bituminous limestone, and serpentine, and values lower by two orders of magnitude were achieved for magnesite and basalt.

The CaL simulations performed for the thermally pretreated samples also demonstrated different degrees of conversion for the tested rock sorbents (Table 2). As predicted, they were the highest for the Stramberk limestone sample, which was characterized by the highest proportion of calcium carbonate. The decrease in conversion with subsequent $\mathrm{CaL}$ cycles was most apparent for the sorbents with the highest values of this parameter. 


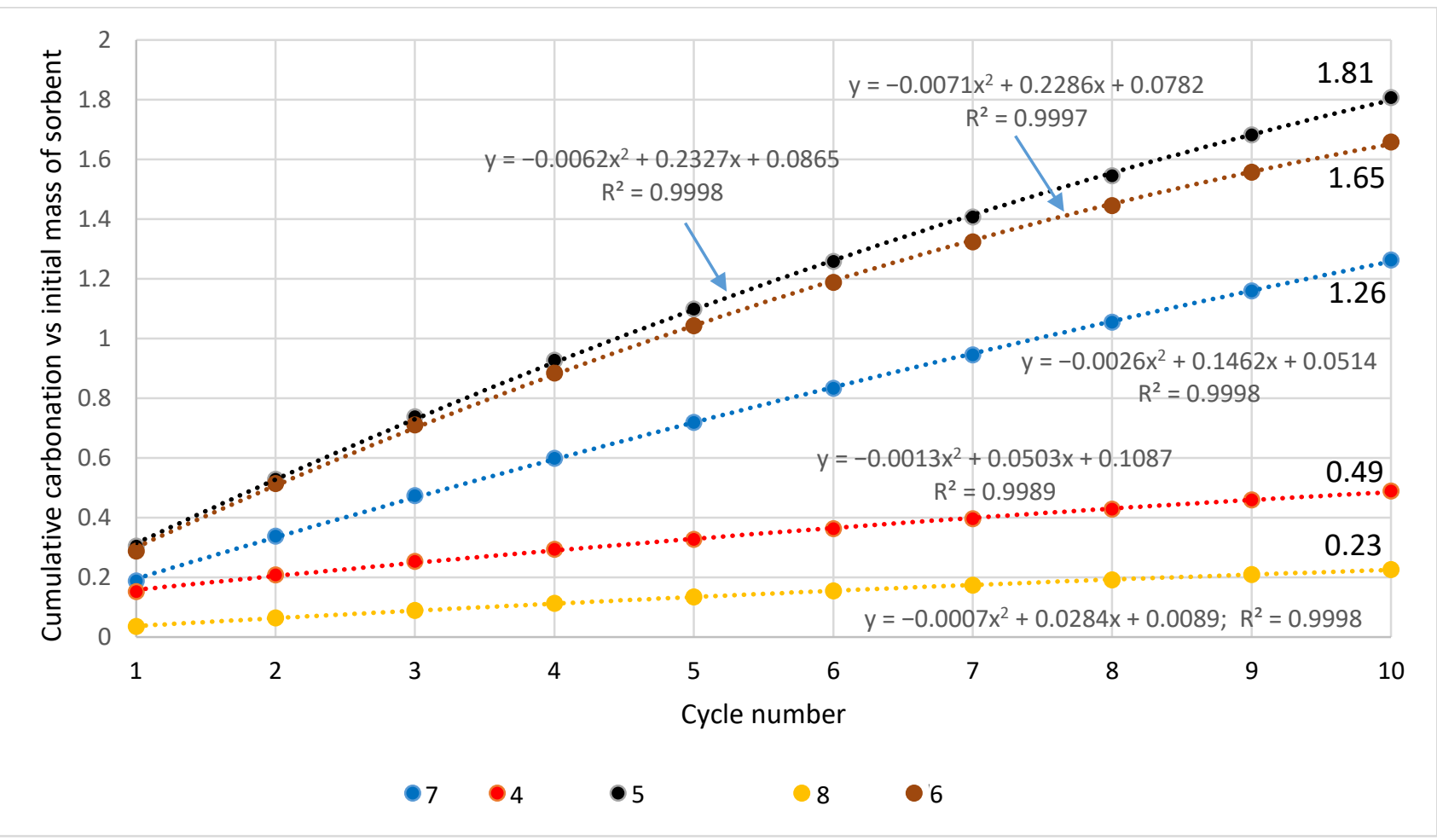

Figure 18. Cumulative carbonation relative to the initial mass of the sorbent-carbonate rocks.

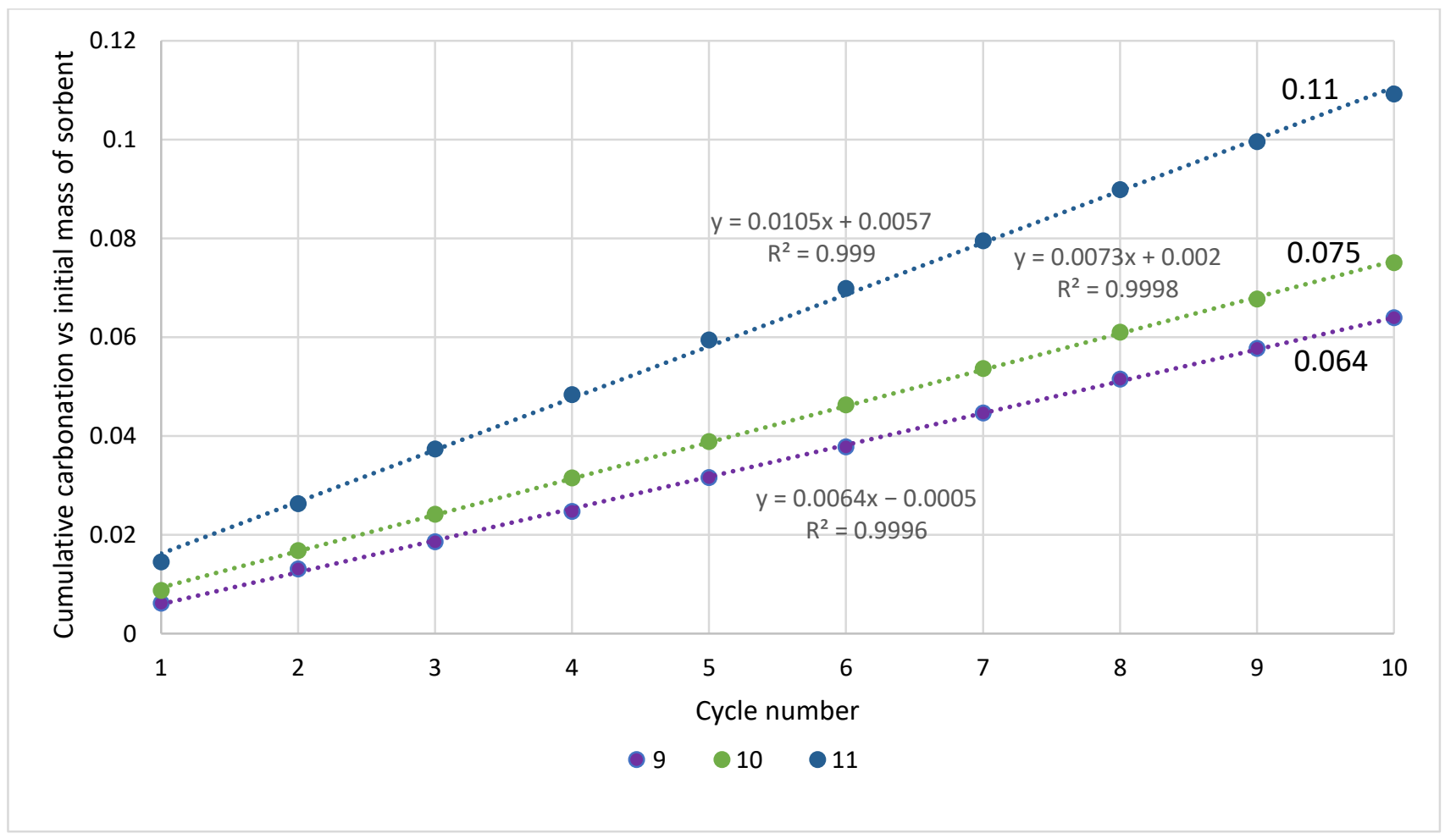

Figure 19. Cumulative carbonation relative to the initial mass of the sorbent-non-carbonate rocks. 
Table 2. Conversion in raw and pretreated limestones.

\begin{tabular}{|c|c|c|c|c|c|c|}
\hline \multirow{4}{*}{ Cycle } & \multicolumn{6}{|c|}{ Sample } \\
\hline & \multicolumn{2}{|c|}{ Štramberk } & \multicolumn{2}{|c|}{ Podlesie } & \multicolumn{2}{|c|}{ Butkov } \\
\hline & \multicolumn{2}{|c|}{$90.1 \% \mathrm{CaCO}_{3}$} & \multicolumn{2}{|c|}{$84.5 \% \mathrm{CaCO}_{3}$} & \multicolumn{2}{|c|}{$68.9 \% \mathrm{CaCO}_{3}$} \\
\hline & Untreated & Pretreated & Untreated & Pretreated & Untreated & Pretreated \\
\hline 1 & 0.73 & 0.24 & 0.61 & 0.14 & 0.28 & 0.09 \\
\hline 2 & 0.59 & 0.22 & 0.49 & 0.12 & 0.17 & 0.08 \\
\hline 3 & 0.51 & 0.21 & 0.42 & 0.12 & 0.13 & 0.08 \\
\hline 4 & 0.46 & 0.20 & 0.38 & 0.11 & 0.11 & 0.07 \\
\hline 5 & 0.43 & 0.19 & 0.34 & 0.11 & 0.10 & 0.07 \\
\hline 6 & 0.40 & 0.19 & 0.31 & 0.11 & 0.09 & 0.07 \\
\hline 7 & 0.37 & 0.19 & 0.28 & 0.11 & 0.09 & 0.06 \\
\hline 8 & 0.35 & 0.19 & 0.25 & 0.10 & 0.09 & 0.06 \\
\hline 8 & 0.33 & 0.18 & 0.23 & 0.10 & 0.09 & 0.06 \\
\hline 10 & 0.32 & 0.18 & 0.21 & 0.10 & 0.08 & 0.06 \\
\hline
\end{tabular}

The cumulative carbonation in the course of the analyzed cycles shows a pattern similar to that of the degree of conversion (Table 3); however, the value of this parameter was more than two times lower than for the raw samples of Stramberk (0.86) and Butkov (0.35). The greatest relative decrease was recorded for the Podlesie limestone, the cumulative carbonation of which decreased by more than three times (from 1.62 for raw sample to 0.5 after thermal treatment) despite the relatively high content of $\mathrm{CaCO}_{3}$.

Table 3. Cumulative carbonation relative to the initial weight of the sorbent for raw and pretreated limestones.

\begin{tabular}{ccccccc}
\hline \multirow{2}{*}{ Cycle } & \multicolumn{2}{c}{ Sample } \\
\cline { 2 - 7 } & \multicolumn{2}{c}{ Štramberk } & \multicolumn{2}{c}{ Podlesie } & \multicolumn{2}{c}{ Butkov } \\
\cline { 2 - 7 } & Untreated & Pretreated & Untreated & Pretreated & Untreated & Pretreated \\
\hline 1 & 0.31 & 0.10 & 0.28 & 0.06 & 0.14 & 0.05 \\
\hline 2 & 0.57 & 0.20 & 0.50 & 0.12 & 0.23 & 0.09 \\
\hline 3 & 0.79 & 0.29 & 0.70 & 0.17 & 0.29 & 0.13 \\
\hline 4 & 0.99 & 0.37 & 0.87 & 0.22 & 0.35 & 0.16 \\
\hline 5 & 1.17 & 0.46 & 1.03 & 0.27 & 0.40 & 0.20 \\
\hline 6 & 1.34 & 0.54 & 1.17 & 0.32 & 0.45 & 0.23 \\
\hline 7 & 1.50 & 0.62 & 1.30 & 0.37 & 0.50 & 0.26 \\
\hline 8 & 1.65 & 0.70 & 1.41 & 0.41 & 0.54 & 0.29 \\
\hline 8 & 1.80 & 0.78 & 1.52 & 0.46 & 0.58 & 0.32 \\
\hline 10 & 1.93 & 0.86 & 1.62 & 0.50 & 0.62 & 0.35 \\
\hline
\end{tabular}

The thermal pretreatment was not effective for the examined limestones, as also reported by Manovic et al. [20]; it is believed to be efficient for only some types of natural materials. It is likely that different types of limestone require different pretreatment conditions due to differences in impurities and internal structures [28]. However, this treatment has clear advantages: It is simple and relatively inexpensive compared to other techniques. On the other hand, it should be underlined that this would require additional energy to heat up the sorbent prior to its final use. This may result in a reduction in the 
power output of a CaL-equipped power generation system. Nonetheless, several studies proved that even if the pretreated limestone shows lower values of initial sorption capacity, this capacity increases over many cycles due to the softening of the hard skeleton. The disadvantage of this refining technique is that although the reactivity increases, the attrition of the particles significantly increases [29].

\section{Summary and Conclusions}

The suitability of selected rocks-limestone, dolomite, magnesite, marl, serpentinite, and basalt-was tested for the purpose of $\mathrm{CO}_{2}$ sequestration in the CaL process. TGA-DSC tests were carried out based on a temperature program designed for this purpose. The tests were performed in 10 cycles of alternating calcination and carbonation. During the measurements, changes in the mass of the sample over time (TGA) and heat flow (DSC) were recorded.

CaL simulations showed various degrees of conversion for the tested rock sorbentsthe highest values were achieved for carbonate rocks (except for bituminous limestone), intermediate values were achieved for marl and bituminous limestone, lower ones were achieved for the remaining sorbents (magnesite and serpentinite), and the lowest were achieved for basalt.

The decrease in the conversion rate with subsequent CaL cycles was most intense for the sorbents with the highest values of this parameter. In the case of basalt, no significant changes in the conversion rate were observed. The decrease in gas capture efficiency with an increasing number of $\mathrm{CaL}$ cycles may be related to the decreasing active sorbent surface due to sintering.

The values of the parameter called "cumulative carbonation relative to the initial mass of the sorbent" corresponded to the multiplicity of the captured $\mathrm{CO}_{2}$ relative to the initial sorbent mass. This parameter, exceeding a value of 1.0, was the highest for carbonate rocks; it achieved lower values for marl, bituminous limestone, and serpentine, as well as - by two orders of magnitude-for magnesite and basalt.

In most of the analyzed samples, the carbonation process was not completed within the assumed time of $10 \mathrm{~min}$. In practice, however, extending the carbonation time could reduce the economics of the capture process.

The simulations of the thermally pretreated samples also demonstrated different degrees of conversion for the tested rock sorbents, which were the highest for the calciumcarbonate-rich Stramberk limestone. The cumulative carbonation of the pretreated samples was more than two times lower than that of the raw ones. The largest relative decrease was recorded in the case of Podlesie limestone, the cumulative carbonation of which decreased by more than three times, despite the relatively high $\mathrm{CaCO}_{3}$ content.

Author Contributions: Conceptualization, methodology, validation, formal analysis, investigation, data curation, writing — original draft preparation, writing — review and editing, visualization, K.L. All authors have read and agreed to the published version of the manuscript.

Funding: This research received no external funding.

Institutional Review Board Statement: Not applicable.

Informed Consent Statement: Not applicable.

Data Availability Statement: The data presented in this study are available on request from the corresponding author.

Conflicts of Interest: The author declare no conflict of interest.

\section{References}

1. International Energy Agency. Energy and Climate Change-World Energy Outlook—Special Briefing for COP21; International Energy Agency: Paris, France, 2015.

2. Olivier, J.G.J.; Janssens-Maenhout, G.; Muntean, M.; Peters, J.A.H.W. Trends in Global CO 2 Emissions-2015 Report; No: JRC98184; PBL Netherlands Environmental Assessment Agency: The Hague, The Netherlands, 2015. 
3. Sanna, A.; Uibu, M.; Caramanna, G.; Kuusik, R.; Maroto-Valer, M.M. A review of mineral carbonation technologies to sequester $\mathrm{CO}_{2}$. Chem. Soc. Rev. 2014, 43, 8049. [CrossRef] [PubMed]

4. Gislason, S.R.; Wolff-Boenisch, D.; Stefansson, A.; Oelkers, E.H.; Gunnlaugsson, E.; Sigurdardottir, H.; Sigfusson, B.; Broecker, W.S.; Matter, J.M.; Stute, M.; et al. Mineral sequestration of carbon dioxide in basalt: A pre-injection overview of the carbfix project. Int. J. Greenh. Gas Contr. 2010, 4, 537-545. [CrossRef]

5. McKelvy, M.J.; Chizmeshya, A.V.G.; Diefenbacher, J.; Béarat, H.; Wolf, G. Exploration of the role of heat activation in enhancing serpentine carbon sequestration reactions. Environ. Sci. Technol. 2004, 38, 6897-6903. [CrossRef] [PubMed]

6. Olajire, A.A. A review of mineral carbonation technology in sequestration of $\mathrm{CO}_{2}$. J. Pet. Sci. Eng. 2013, 109, 364-392. [CrossRef]

7. Werner, M.; Verduyn, M.; van Mossel, G.; Mazzotti, M. Direct flue gas CO2 mineralization using activated serpentine: Exploring the reaction kinetics by experiments and population balance modelling. Energy Procedia 2014, 4, 2043-2049. [CrossRef]

8. Huijgen, W.J.J.; Comans, R.N.J. Carbon Dioxide Sequestration by Mineral Carbonation: Literature Review; ECN-Clean Fossil Fuels Environmental Risk Assessment: Petten, The Netherlands, 2003; p. 112.

9. Kirsch, $\mathrm{K} . \mathrm{CO}_{2}$-Induced Metal Release from Sandstones: Implications for Geologic Carbon Sequestration. Master's Thesis, Hydrologic Science and Engineering Faculty, School of Mines, Golden, CO, USA, 2013.

10. Blamey, J.; Anthony, E.J.; Wang, J.; Fennell, P.S. The calcium looping cycle for large-scale $\mathrm{CO}_{2}$ capture. Prog. Energy Combust. Sci. 2010, 36, 260-279. [CrossRef]

11. Laursen, K.; Duo, W.; Grace, J.R.; Lim, J. Sulfation and reactivation characteristics of nine limestones. Fuel 2000, 79, 153-163. [CrossRef]

12. Dean, C.C.; Blamey, J.; Florin, N.H.; Al-Jeboori, M.J.; Fennell, P.S. The calcium looping cycle for $\mathrm{CO}_{2}$ capture from power generation, cement manufacture and hydrogen production. Chem. Eng. Res. Des. 2011, 89, 836-855. [CrossRef]

13. Mantripragadaa, H.C.; Rubin, E.S. Calcium looping cycle for $\mathrm{CO}_{2}$ capture: Performance, cost and feasibility analysis. Energy Procedia 2014, 63, 2199-2206. [CrossRef]

14. Lee, D. An apparent kinetic model for the carbonation of calcium oxide by carbon dioxide. Chem. Eng. J. 2004, 100, 71-77. [CrossRef]

15. Oakeson, W.G.; Cutler, I.B. Effect of $\mathrm{CO}_{2}$ Pressure on the Reaction with CaO. J. Am. Ceram. Soc. 2006, 62, 556-558. [CrossRef]

16. Butler, J.; Lim, J.; Grace, J. Kinetics of $\mathrm{CO}_{2}$ absorption by $\mathrm{CaO}$ through pressure swing cycling. Fuel 2014, 127, 78-87. [CrossRef]

17. Levenspiel, O. Chemical Reaction Engineering, 2nd ed.; John Wiley and Sons: New York, NY, USA, 1972.

18. Salvador, C.; Lu, D.; Anthony, E.J.; Abanades, J.C. Enhancement of $\mathrm{CaO}$ for $\mathrm{CO}_{2}$ capture in an FBC environment. Chem. Eng. J. 2003, 96, 187-195. [CrossRef]

19. González, B.; Blamey, J.; McBride-Wright, M.; Carter, N.; Dugwell, D.; Fennell, P. Calcium looping for CO2 capture: Sorbent enhancement through doping. Energy Procedia 2011, 4, 402-409. [CrossRef]

20. Manovic, V.; Anthony, E.J. Lime-Based sorbents for high-temperature $\mathrm{CO}_{2}$ capture-A review of sorbent modification methods. Int. J. Environ. Res. Public Health 2010, 7, 3129-3140. [CrossRef]

21. Li, Y.J.; Zhao, C.S.; Duan, L.B.; Liang, C.; Li, Q.Z.; Zhou, W. Cyclic calcination/carbonation looping of dolomite modified with acetic acid for $\mathrm{CO}_{2}$ capture. Fuel Process. Technol. 2008, 89, 1461-1469. [CrossRef]

22. Ridha, F.N.; Manovic, V.; Macchi, A.; Anthony, E.J. The effect of $\mathrm{SO}_{2}$ on $\mathrm{CO}_{2}$ capture by CaO-based pellets prepared with a kaolin derived $\mathrm{Al}(\mathrm{OH})_{3}$ binder. Appl. Energy 2012, 92, 415-520. [CrossRef]

23. Erans, M.; Manovic, V.; Anthony, E.J. Calcium looping sorbents for $\mathrm{CO}_{2}$ capture. Appl. Energy 2016, 180, 722-742. [CrossRef]

24. Albrecht, K.O.; Wagenbach, K.S.; Satrio, J.A.; Shanks, B.H.; Wheelock, T.D. Development of a CaO-based sorbent with improved cyclic stability. Ind. Eng. Chem. Res. 2008, 47, 7841-7848. [CrossRef]

25. Manovic, V.; Anthony, E.J. Thermal Activation of CaO-Based Sorbent and Self-Reactivation during $\mathrm{CO}_{2}$ Capture Looping Cycles. Environ. Sci. Technol. 2008, 42, 4170-4174. [CrossRef]

26. Manovic, V.; Anthony, E.J.; Grasa, G.; Abanades, J.C. $\mathrm{CO}_{2}$ Looping Cycle Performance of a High-Purity Limestone after Thermal Activation/Doping. Energy Fuels 2008, 22, 3258-3264. [CrossRef]

27. Lysikov, A.I.; Salanov, A.N.; Okunev, A.G. Change of $\mathrm{CO}_{2}$ carrying capacity of $\mathrm{CaO}$ in isothermal recarbonation-decomposition cycles. Ind. Eng. Chem. Res. 2007, 46, 4633-4638. [CrossRef]

28. Arias, B.; Grasa, G.S.; Alonso, M.; Abanades, J.C. Post-combustion calcium looping process with a highly stable sorbent activity by recarbonation. Energy Environ. Sci 2012, 5, 7353-7359. [CrossRef]

29. Chen, Z.; Song, H.S.; Portillo, M.; Lim, C.J.; Grace, J.R.; Anthony, E.J. Long-term calcination/carbonation cycling and thermal pretreatment for $\mathrm{CO}_{2}$ capture by limestone and dolomite. Energy Fuels 2009, 23, 1437-1444. [CrossRef] 